\title{
A novel and precise on-line digital measurement of unsaturated phase inductance of a switched reluctance motor
}

\author{
DEVRAJ ROY*D and MAINAK SENGUPTA \\ Department of Electrical Engineering, Indian Institute of Engineering Science and Technology, \\ Shibpur, Howrah 711103, India \\ e-mail: devraj.roy.rs2016@ee.iiests.ac.in; msg@ee.iiests.ac.in
}

MS received 29 October 2018; revised 17 March 2019; accepted 9 August 2019

\begin{abstract}
This paper presents a simple and accurate method for the on-line measurement of the unsaturated phase inductance of a switched reluctance motor (SRM). The basic principle behind the approach is to obtain the instantaneous flux linkage of the phase, which when divided by the instantaneous current of the corresponding phase will dynamically generate the phase inductance for that rotor position. A numerical division process, based on Newton-Raphson (N-R) iterative method, has been implemented using the sensed current and estimated flux linkage on an FPGA platform to generate the inductance value at each instant. It is ensured in the practical implementation that the iron parts do not saturate. It has been also verified through simulation using standard finite-element method (FEM) software packages. Further, it has been established that the effect of mutual inductance is negligibly small. The proposed method will give the true value of the unsaturated inductance of the phase identified for diagnosis/measurement. Practical results, for the experiments conducted on an existing $4 \mathrm{~kW}, 1500 \mathrm{rpm}$ Oulton-make SRM, have been also presented. They are further validated against the results obtained from FEM analysis and against previously published results of the phase inductance values for this SRM. The results are found to be in very good agreement.
\end{abstract}

Keywords. Switched reluctance motor; on-line inductance measurement; magnetic saturation; NewtonRaphson method; hysteresis switching; FEM analysis.

\section{Introduction}

A switched reluctance motor (SRM) is, in principle, a variable reluctance stepper motor running in closed loop with position feedback $[1,2]$. The double saliency of the motor gives rise to a variable reluctance in the magnetic circuit of each phase and hence a variable inductance profile versus rotor position for each phase. Accurate modelling of the phase inductance versus rotor position of the motor is essential for design validation, performance analysis and developing non-linear or piece-wise linear models of the motor [3-5]. Both analysis and measurement methods have been proposed in the literature for actual knowledge of the inductance profile of the motor. In the most simple way (neglecting the effects of fringing and leakage flux), the inductance profile can be obtained analytically by overlap method [1-3] and is nearly trapezoidal in nature $[4,5]$. The presence of leakage and fringing flux has two effects on the inductance profile, namely, (i) it enhances the effective inductance value for all positions and (ii) it also causes rounding of the corners of the trapezoidal inductance profile as obtained by overlap

*For correspondence

Published online: 19 October 2019 method. Researchers have proposed non-linear techniques $[6,7]$, Fourier series expansion method [8] and soft computing techniques, e.g., artificial neural network (ANN) [9] and least-square support vector machine (LSSVM) [10], for precise analytical derivation of $L(\theta)$ profile versus rotor position. The approaches [6-10] are novel at the cost of complexity, huge memory space requirement, large computational time and requirement of high-end computational platform. A more generic and fast method for the analytical estimation had been proposed in $[2,11]$ by extending the concepts proposed by Pohl [12] for inductor alternators in 1946, to SRM. Figure 1 shows the cross-sectional view of the 4-phase 8/6 (8 stator and 6 rotor poles) Oulton-make SRM (set-up under test). The corresponding $L(\theta)$ profiles of the motor are shown in figure 2 (as obtained by Pohl's method in $[1-3,11]$ and trapezoidal ideal inductance profile in [1-5]), which show the effects of leakage and fringing flux as mentioned earlier; $\theta_{a}$ and $\theta_{u}$ represent, respectively, the perfectly aligned and unaligned positions of the rotor teeth with regard to the stator pole axis; $\theta_{0}$ (the point of rising inductance for the trapezoidal idealised inductance profile) is considered as the reference $\left(0^{\circ}\right)$ commutation instant of the phases. Angular interval of commutation prior to $\theta_{0}$ instant (i.e. left of the $\theta_{0}$ axis) has been referred to as 


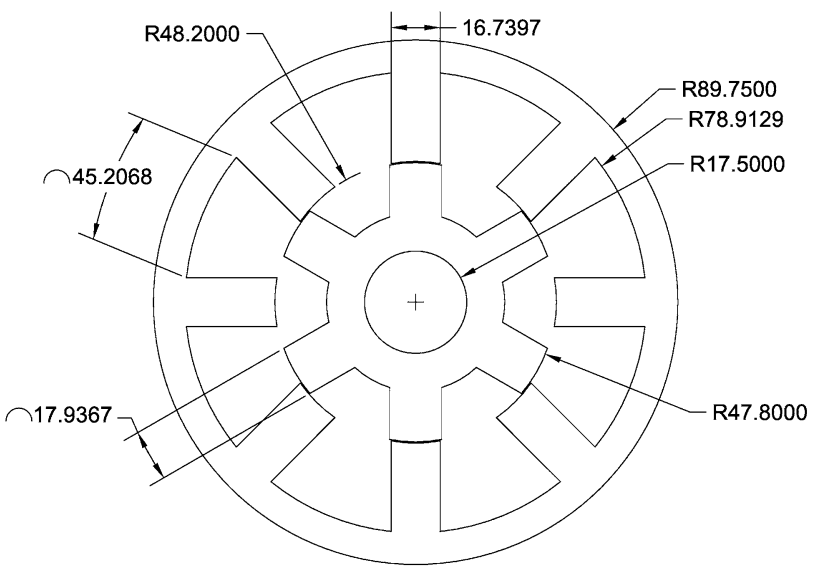

Figure 1. A 2-D cross-sectional view of a 4-phase Oulton SRM.

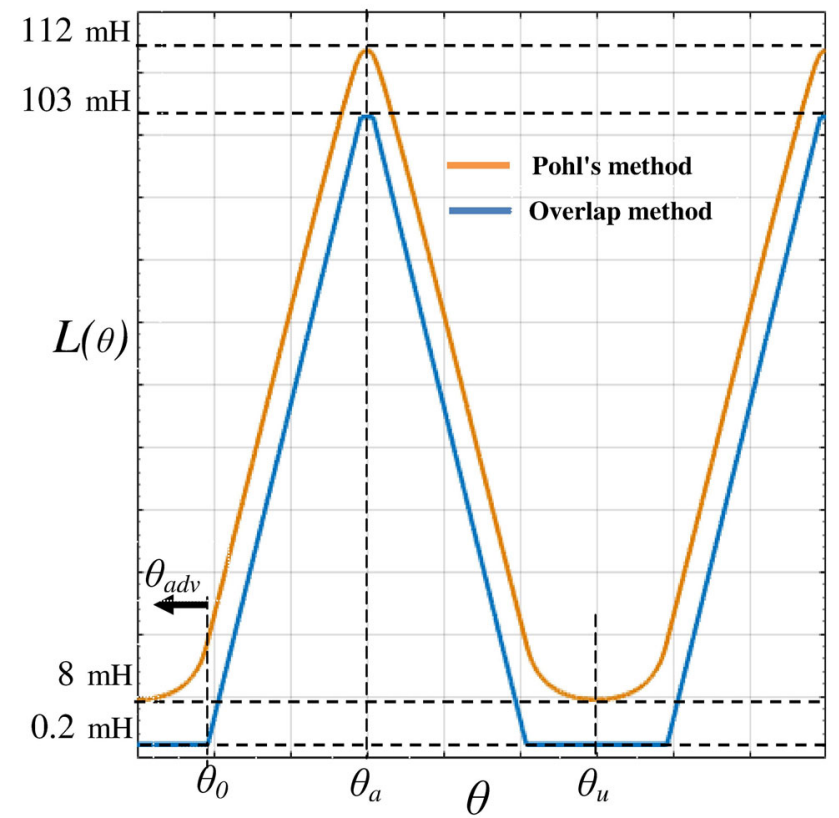

Figure 2. A typical $L-\theta$ profile of Oulton SRM obtained by Pohl's method.

the angle of advance $\left(\theta_{a d v}\right)[1-3]$. Thus, a turn-on of a phase at $\theta_{0}$ instant may be treated as $\theta_{a d v}=0^{\circ}$.

Due to the variation of the phase inductance of the motor with rotor position and additionally with saturation of the iron parts, it is a challenge to measure/evaluate it precisely throughout the rotor pitch (here, $\frac{360^{\circ}}{6}=60^{\circ}$ ). Unlike conventional electrical machines, there is no known standard method available in the literature. In a broad perspective, the measurement methods can be categorised as off-line and on-line methods. In case of off-line measurements, the recorded data of applied phase voltage, using either a single-phase AC supply [13, 14] or a pulsed DC source [15-19], and phase currents are obtained from the repeated experiments performed by locking the rotor of an SRM at different angular positions. They are further processed either analytically or by means of a software subroutine in a computer [13-19]. The precision of the methods [13-19] depends on the locking mechanism and the resolution of angular rotation of the rotor in each step of measurement. Moreover, the methods also require extra mechanical arrangements and hardware to rotate and lock the rotor precisely at planned discrete and numerous positions throughout the rotor tooth pitch. A precise knowledge of the inductance profile is essential for SRM operation and performance evaluation as will be clear from the subsequent discussion. Therein lies the importance of the present work, which seeks to estimate the instantaneous value of the phase inductance very precisely for an SRM under running conditions even in the presence of bulk saturation (coupled with concepts presented in $[2,11]$ ).

Recent research trends show renewed focus on inductance-based sensorless operation of the motor, which lead to the development of on-line methods for the measurement/estimation of the phase inductance. Advanced techniques, like ANN and recursive least-square estimator (RLSE), have been developed in [20] and [21], respectively. The methods lead to significant computational burden, require large memory space and also a prior proper training of the model. A novel method based on high-frequency diagnostic pulse injection has been proposed in [22-25] for the measurement of the phase inductance. In the methods presented in [20-25], the authors have not analysed the effect of saturation of the motor iron parts. Saturation has a very significant influence on the dynamically estimated/measured value of inductance for each rotor position.

The components of phase inductance of an SRM, depending upon the magnetic circuit of each phase and saturation of the motor iron, have been categorised as 'air gap inductance', 'unsaturated inductance' and 'saturated inductance' in [1-3, 11]. It may be easily appreciated that if iron parts are assumed to be infinitely permeable then there will be no MMF drop in the iron parts and the phase inductance $L_{p h}$ would have been $N^{2} \mathcal{P}$, where $\mathcal{P}=\frac{\phi}{\mathcal{F}}=$ $\frac{\phi}{N i_{g}(=N i)}=\frac{N \phi}{N^{2} i}=\frac{\psi}{N^{2} i}$, or $N^{2} \mathcal{P}=L_{p h}=\frac{\psi}{i}$, where the symbols have their usual meanings. That is, the inductance of doubly salient structure would have been due to the presence of air gap alone. This is well explained by the authors in $[1-3,11]$. This has been referred to as the 'air gap inductance' by the authors here following [1-3, 11]. Additionally, if the MMF drop in motor iron is negligibly small compared with the MMF drop in the magnetic circuit of each phase then the phase inductance $L_{p h}=\frac{\psi}{i}$ has been termed as 'unsaturated inductance' of the phase $[1-3,11]$. This has been detailed later in section 2 . The authors in $[2,11,26]$, under bulk saturation of the iron parts, had presented a novel approach for on-line measurement of the phase 'air gap inductance' of the four phases of an inprocess SRM. It is obtained dynamically through analogue 
division of flux linkage and the appropriate component of phase MMF (currents) during the conduction interval of each phase without involving any extra computational hardware or introduction of diagnostic pulses $[2,11]$.

The present work can be treated as a sequel to the aforementioned approach proposed by Sengupta and co-workers $[2,11]$, where the work has been extended to obtain the periodic unsaturated inductance profile (for an entire tooth rotation period, which is $60^{\circ}$ mech and $360^{\circ}$ elec) of one phase of an SRM using an FPGA platform for the dynamic evaluation. However, the earlier work $[2,11]$ measured both the 'unsaturated inductance' and the 'air gap inductance' of the excited phase for the conduction interval equal to the step angle, $\theta_{\text {step }}$ (i.e. during which the phase remains excited) only. This extension may be considered as a significant addition to the previous work in $[2,11]$. The authors also claim novelty of the present work in terms of absence of any additional computational platform over and above that required to operate the SRM-based drives. Additional mechanical hardware is also not used for locking the rotor precisely at planned discrete positions, unlike [13-19]. Apart from this, the proposed method being online in nature does not utilise any soft computing/regression techniques for prior training/learning of the model unlike $[20,21]$. This reduces the computational burden and requirement of large memory space. The proposed method has been realised with much less logic elements (1163) also on the chosen digital platform. The method does not need any injection of diagnostic pulses in the phases to obtain the periodic inductance profile, unlike [22-25]. This may be considered as another significant contribution over the present state of art.

As mentioned earlier, the FPGA platform may be treated as an integral part of the SRM drive system since it acts as a control platform for open loop as well as closed loop operation even otherwise. The method, as proposed here, is an on-line process that requires only one voltage and current sensors to measure the DC-bus voltage and the appropriate phase currents (whose inductances are to be measured), respectively. The same has been implemented on an existing 4-phase, $4 \mathrm{~kW}, 300 \mathrm{~V}, 1500 \mathrm{rpm}$ Oultonmake SRM set-up (figure 1 and mechanical dimensions and ratings are given in tables 2 and 3, respectively) available in the laboratory. The test results of the motor are also available in the published work of Sengupta and co-workers $[2,11]$, which are used as a bench-mark to verify the accuracy of the proposed method.

\section{Basic principles of the proposed method}

The instantaneous inductance of a phase of an SRM is obviously given by

$$
L(\theta)=\frac{\psi}{i}
$$

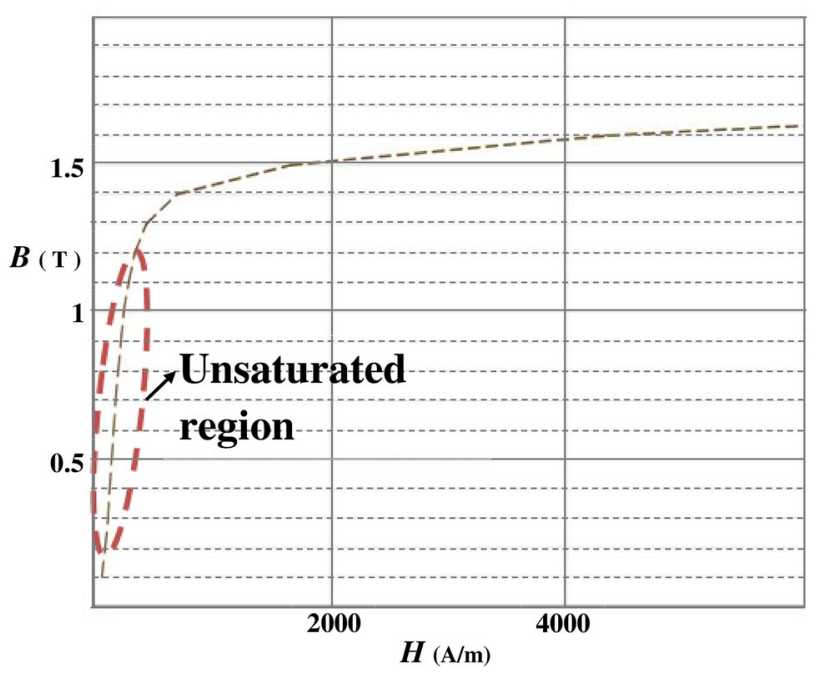

Figure 3. $B-H$ curve of electrical steel material.

where $\psi$ and $i$ are the instantaneous values of phase flux linkage and the current of the phase winding, respectively. The lamination material of the experimental motor is not known to us. To continue with the analysis, the $B-H$ characteristics [27] of standard electrical steel material (figure 3) have been considered. It has poorer characteristics (i.e., larger $H$ for a given $B$ ) compared with usual electrical machine lamination material, available presently. If the operating point is ensured to lie in the linear zone (shown encircled in figure 3), the motor iron (assuming uniform flux density and isotropy everywhere in the iron parts) can be treated as unsaturated. Hence, following (1), the dynamic division of $\psi$ and corresponding phase current $i$ will result in the instantaneous unsaturated phase inductance of the motor.

\subsection{Analysis of the magnetic circuit of the motor}

Figure 4 shows the equivalent lumped parameter magnetic circuit of a phase of the SRM where the subscripts $s, r, t, y$ represent stator, rotor, tooth and yoke, respectively. For example, the term $\mathcal{R}_{s y}$ implies the reluctance of stator yoke. The series path reluctances for two air gaps, rotor teeth and stator teeth (including the pole) have been lumped together.

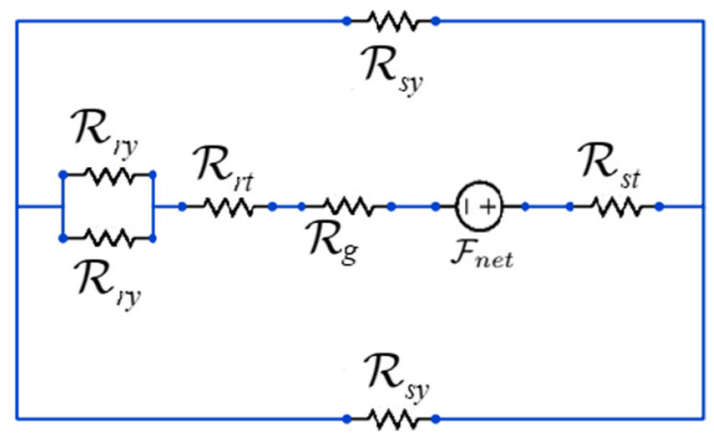

Figure 4. Equivalent magnetic circuit of one phase of the SRM. 
The parallel path reluctances have been separately shown (stator yoke and rotor core). Neglecting leakage and fringing, the instantaneous net MMF, $\mathcal{F}_{\text {net }}$, is given in terms of the air gap flux as

$$
\begin{aligned}
\mathcal{F}_{\text {net }} & =\phi \mathcal{R}_{g}+\phi \mathcal{R}_{\text {iron }} \\
\Rightarrow i & =i_{g}+i_{\text {iron }},
\end{aligned}
$$

where $\mathcal{R}_{\text {iron }}=\mathcal{R}_{s t}+\mathcal{R}_{r t}+\frac{\mathcal{R}_{s y}+\mathcal{R}_{r y}}{2}$ and $\mathcal{R}_{g}$ represents lumped series path reluctance for two air gaps. Here $i_{g}, i_{\text {iron }}$ are conceptual fictitious quantities representing those parts of the current that account for the MMF drop in air gap and iron, respectively. From (1) and (2) we get

$$
L=\frac{\psi}{i_{g}+i_{\text {iron }}} .
$$

Following [11], the iron ATs can be separated from phase current in (2). From (3), the phase inductance is hence given by

$$
L=\frac{\psi}{i_{g}} .
$$

Expression (4) corresponds to 'air gap inductance' (as different from unsaturated inductance) of the motor phase as in $[2,11]$, where it is evaluated/measured during conduction interval of the phases, as clarified in the previous section. In this paper, the authors propose an alternative approach where, following (1), the instantaneous periodic unsaturated phase inductance of the motor has been measured/evaluated. The unsaturated state of the motor iron has been ensured by maintaining a low average value of phase current during the process of measurement. This is an extension of the work in $[2,11]$ since the measurement of unsaturated phase inductance over an entire rotor tooth rotational period $\left(60^{\circ}\right.$ mech and $360^{\circ}$ elec of phase) can be done instead of evaluating only a part of it during the conduction interval $\left(15^{\circ}\right.$ mech, $90^{\circ}$ elec in $\left.[2,11]\right)$ of each phase.

\subsection{The division process}

From Eq. (1), it follows that the unsaturated phase inductance, $L_{\text {unsat }}$, can be obtained from the division of $\psi$ by $i$. The dynamic division process has been realised numerically by the Newton-Raphson (N-R) method $[28,29]$ in the FPGA platform. The mathematical formulation of the iterative process is given in [28], with $x_{i+1}=x_{i}+\frac{f(x)}{f^{\prime}(x)}$, having an error $\varepsilon_{i+1}=\varepsilon_{i}^{2}$. The quadratic convergence of the error results in a very fast and accurate solution but at the cost of a slow initial convergence for a poor initial estimate of $x_{0}$. In some cases it may not even converge if the initial guess is far away from the solution. To obtain the closest correct initial value, minimax linear approximation method has been used [30]. The initial guess is given by the firstorder polynomial

$$
x_{0}=T_{1}+T_{2} D
$$

with a maximum initial error of $\frac{-T_{1}^{2}}{4 T_{2}}-1 . T_{1}$ and $T_{2}$ are constants whose values are obtained with the constraint of minimising the maximum initial error in the chosen division range $[30,31] . D$ is the variable whose inverse is to be calculated. A flow chart of the N-R division method is shown in figure 5 .

To start with the process, first the boundary is decided upon to avoid any division process instability and digital overflow. It is then utilised to obtain the values of the constants $\left(T_{1}\right.$ and $\left.T_{2}\right)$ that are required to compute the closest correct initial guess from (5). Thereafter, N-R iterations are executed till convergence is achieved. Whenever the error falls within the set tolerance limit of $3 \%$, the output is updated. This also triggers a new input from the ADC, whose initial guess is computed again from (5). It is updated with a delay of $1.25 \mu$ s with respect to the rising edge of the pulse [ch2] shown in figure 6; it updates the output and also triggers a new input value.

For verifying the correctness of the division process and for calibrating the values in the chosen digital platform, a saw tooth waveform, shown in figure 7 (CH1), has been used. It has a frequency of $6.25 \mathrm{kHz}$. For the sake of experimental verification of analytically calculated results only one period may be considered, whose equation is given by

$$
x=3100 t+1, \quad 0 \leq t \leq 3100 .
$$

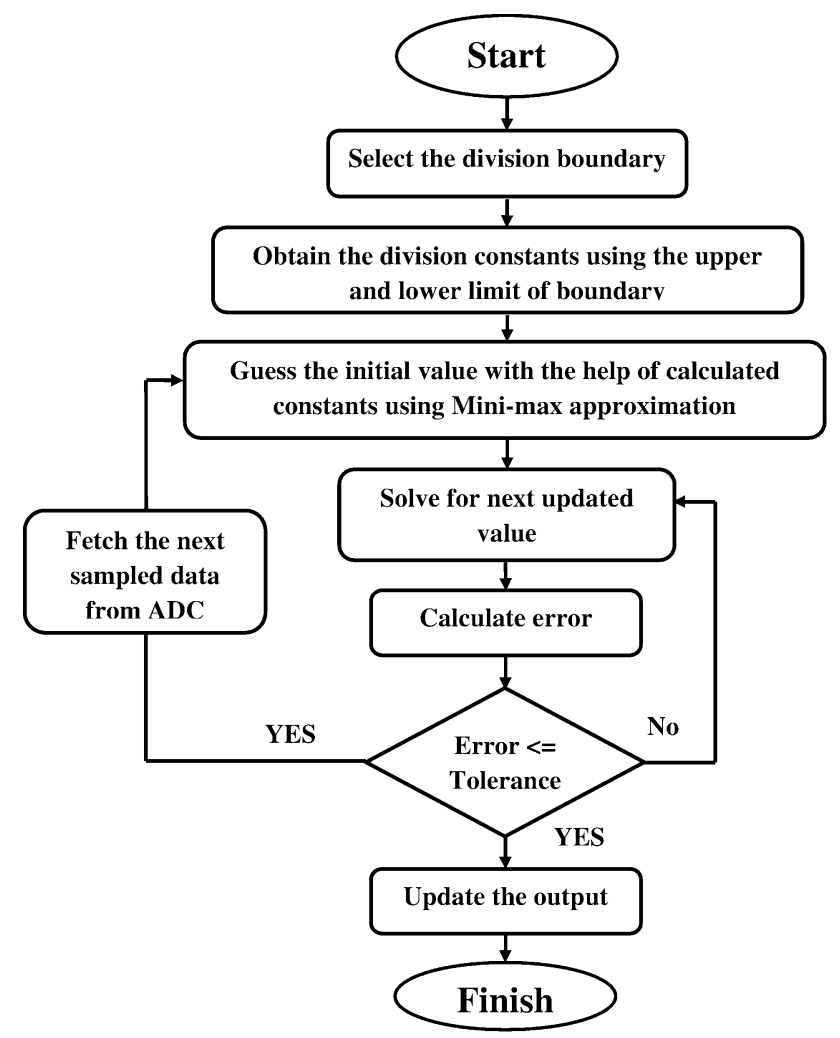

Figure 5. Flow chart of N-R division process. 


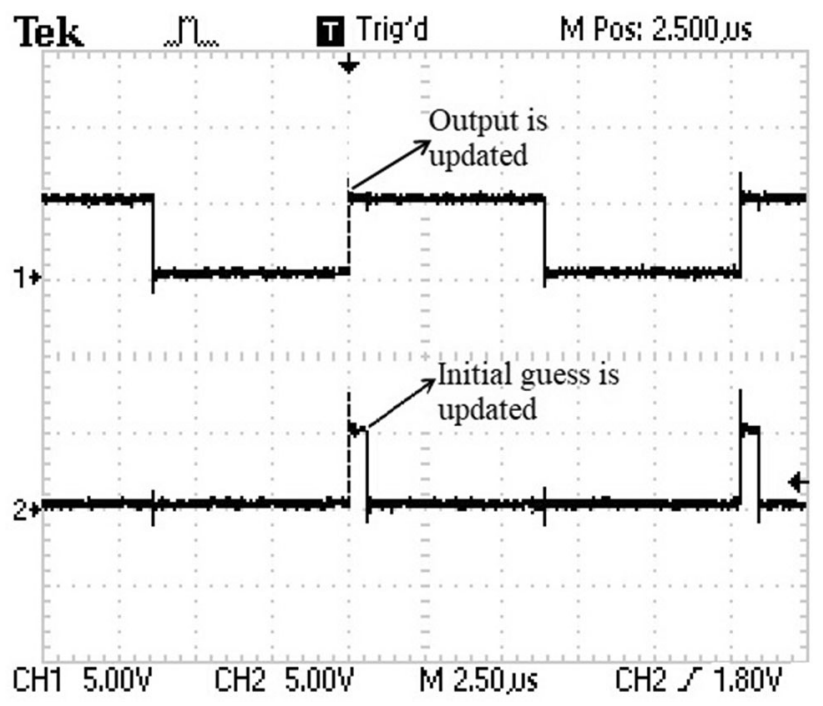

Figure 6. Waveform of the pulses showing the instant of update of output and initial guess.

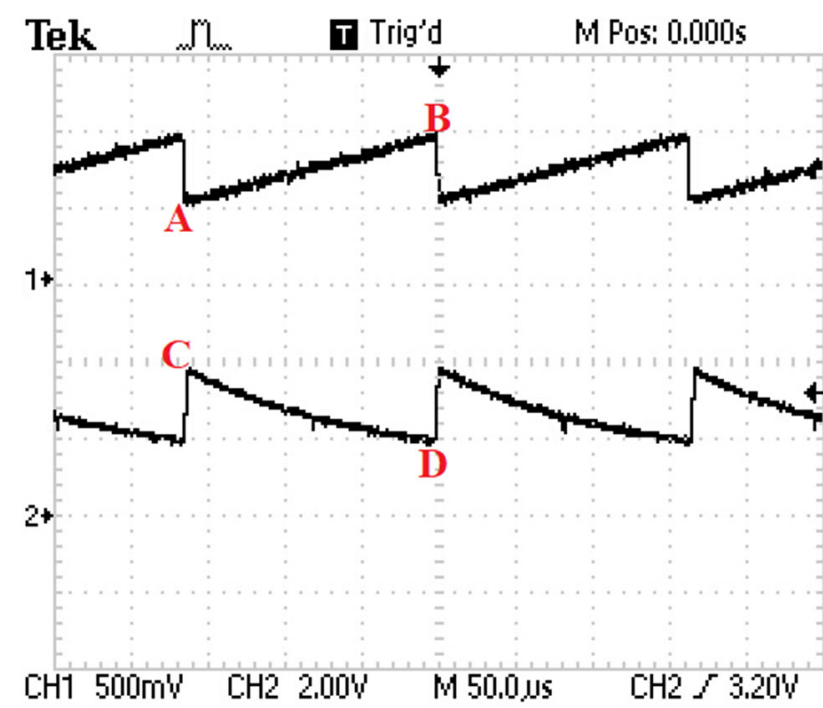

Figure 7. Waveform of division result $(\mathrm{CH} 2)$ along with the saw tooth curve $(\mathrm{CH} 1)$.

It follows from (6) that at $t=0$ and $t=\frac{1}{3100}$ the saw tooth will have a value of 1 and 2 . Taking $x_{\text {base }}=3$, the minimum and maximum PU values are 0.33 and 0.66 , respectively. In the present case, $1 \mathrm{PU}$ has been taken equal to $1.25 \mathrm{~V}$. Thus, the saw tooth will have a voltage range of 0.4125 $0.825 \mathrm{~V}$ as shown in figure 7 ( $\mathrm{CH} 1$ : A \& B, respectively). The inverse of the saw tooth waveform, $\frac{1}{x}$, is shown in figure $7(\mathrm{CH} 2)$. It is hyperbolic in nature. It is elementary to understand that the inverse of the straight line is a hyperbola and the same is validated here. At the minimum and the maximum instants of the saw tooth ( $\mathrm{A}$ and $\mathrm{B}$, figure 7), where it is 0.33 and $0.66 \mathrm{PU}, \frac{1}{x}$ results in $3 \mathrm{PU}\left(\frac{1}{0.33}\right)$ and 1.5 $\left(\frac{1}{0.66}\right) \mathrm{PU}$, which corresponds to voltage levels of 3.75 and $1.875 \mathrm{~V}$, respectively ( $\mathrm{C}$ and $\mathrm{D}$, figure 7 ). The experimental result agrees with the analytical nature and the calculated values at chosen points of the curve, thus establishing the precision and correctness of the division algorithm implemented here.

\subsection{Selection of hysteresis method}

To obtain the periodic unsaturated phase inductance profile of a phase of the motor, a constant current is maintained throughout the electrical period of the phase without causing any significant MMF drop due to the saturation of the iron parts. Hysteresis switching is one of the simplest methods known to limit the phase current within a fixed band (a conventional PI controller has been avoided due to the requirement of continuous gain scheduling, which depends on instantaneous $L$ ). It may be realised in two ways: (a) uni-polar switching and (b) bi-polar switching. Though bi-polar switching has been used in the proposed method, the following points are still worth noting.

(i) In case of the usual uni-polar hysteresis switching, one of the switches of a given leg of the converter is turned off whenever the current touches the upper limit. This allows a free-wheel mode of operation as the current slowly ramps down to the lower limit with $0 \mathrm{~V}$ across the phase. Figure 8 shows a simulated $\psi-i$ curve of phase-R (concerned phase), which is operated with uni-polar hysteresis switching. The waveform is divided into three zones (zones $1-3$ ) as shown in figure 8 . The phase current is maintained constant at an average value of 1.9 A with a peak-to-peak ripple band of $0.2 \mathrm{~A}$. Zone 1 shows the initial rise of phase current without any hysteresis operation (as the current has not entered the band yet) whereas zone 3 represents the interval after $\theta_{\text {step }}$ when both the switches of the leg are turned off. Zone 2 shows the hysteresis switching where $\psi$ is rising for a constant current in the phase. This is expected as the average phase voltage across the winding during the hysteresis period is positive. Thus, if the uni-polar hysteresis switching is used to maintain a constant current in the phase for a complete electrical period, numerically $\psi$ will rise till a digital overflow. The effect, in the physical system, may be visualised as the saturation of the motor iron. Hence, it is not implemented.

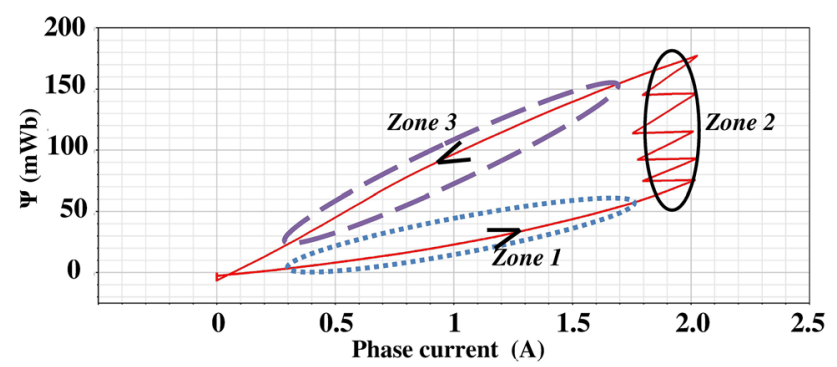

Figure 8. Simulated $\psi-i$ curve of phase-R operated with unipolar hysteresis switching. 
(ii) The alternative approach is bi-polar hysteresis switching where both the switches of the motor are turned off whenever the current touches the upper limit. The current will ramp down to the lower limit with the full reverse DCbus voltage across the phase. It will be shown analytically in the subsequent paragraphs that despite a non-zero average voltage across the winding in each hysteresis switching cycle, the bi-polar switching results in a numerically bounded $\psi$ in the complete electrical period. Hence, it has been implemented here to obtain a constant current in the phase.

Analytical justification of bi-polar hysteresis switching: The typical inductance profile of the SRM is shown again in figure 9. It is assumed that a total of $n$ switchings occur in an electrical period (shown by line 'AB' and 'CD') with a turnon of the switching devices of the phase at ' 1 ' and ' $n-1$ ', respectively. The inductance profile is discretised in each switching cycle as shown in figure 9. (It has been shown (section 3.2) that the minimum switching frequency, for the chosen peak-to-peak set band of $0.2 \mathrm{~A}$, is approximately 1 $\mathrm{kHz}$ in the $L_{\max }$ region. The corresponding electrical frequency of the motor is approximately $30 \mathrm{~Hz}$ (figure 12, section 3.3), which is very slow with respect to $1 \mathrm{kHz}$ switching frequency. Hence, the discretisation of the inductance profile in each switching cycle will not considerably affect correctness of the theoretical justification). Each incremental change in $L$ is represented by $\triangle L$ such that $\triangle L_{k}=L_{k}-L_{k-1}$. The corresponding slope $\mathcal{K}_{k}$ at $k^{\text {th }}$ instant is defined as $\mathcal{K}_{k}=\frac{L_{k}-L_{k-1}}{\triangle \theta}$. Let us consider a $k^{\text {th }}$ switching cycle where the switches are turned on and off at $k^{\text {th }}$ and $k+1^{\text {th }}$ instant, respectively. Following (1), the differential equations of $\psi$ in terms of $L(\theta)$ and $i$ are given by

$$
d \psi=L(\theta) d i+i d L(\theta) .
$$

For the simplicity of the analysis, the phase current is considered to be constant at lower and upper limit of $I_{1}$ and

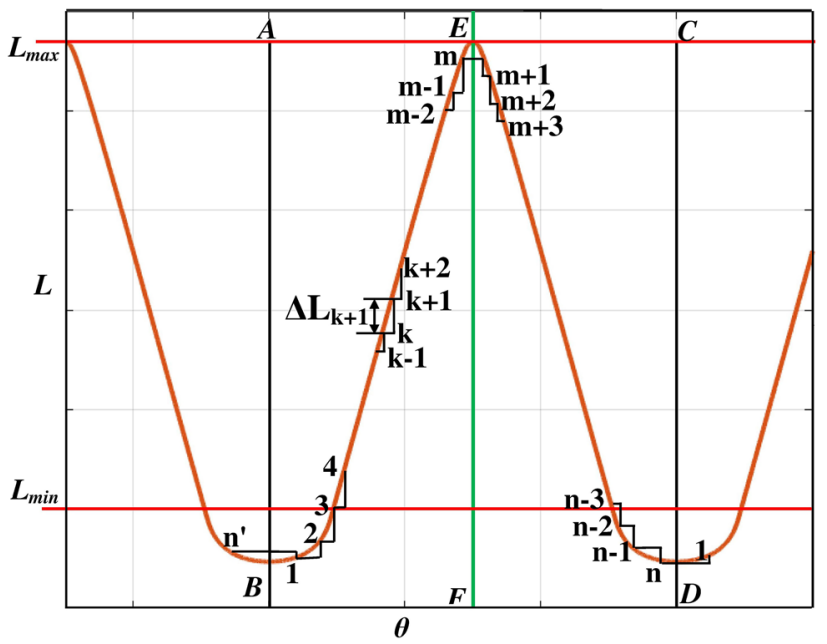

Figure 9. Typical $L-\theta$ profile of the motor showing discretisation in each switching frequency.
$I_{2}$ during the $\mathrm{ON}$ and $\mathrm{OFF}$ duration, respectively. Linearising (7) in these two modes, we get, in ON-mode:

$$
\begin{aligned}
\delta \psi_{k} & =L_{k} \Delta i+I_{1} \triangle L_{k} \\
& =L_{k} \triangle I+\left(L_{k}-L_{k-1}\right)\left(I-\frac{\triangle I}{2}\right) .
\end{aligned}
$$

Similarly, in OFF-mode:

$$
\delta \psi_{k+1}=-L_{k+1} \Delta I+\left(L_{k+1}-L_{k}\right)\left(I+\frac{\triangle I}{2}\right)
$$

where $\delta \psi_{k}$ and $\delta \psi_{k+1}$ are the incremental changes in flux linkage, respectively, during the $\mathrm{ON}$ and OFF duration and $\Delta I$ is the peak-to-peak ripple in the phase current. Addition of (8) and (9) will give the net change in $\psi$ at $k^{\text {th }}$ switching cycle as

$$
\Delta \psi_{k}=\frac{\Delta I}{2}\left(L_{k-1}-L_{k+1}\right)+I\left(\Delta L_{k}+\Delta L_{k+1}\right) \text {. }
$$

Now, adding all the net changes in $\psi$ (in each switching cycle) for the complete electrical period we get

$$
\begin{aligned}
\sum \Delta \psi= & \Delta \psi_{1}+\Delta \psi_{3}+\cdots+\Delta \psi_{m}+\cdots+\Delta \psi_{n-1} \\
= & I\left(\Delta L_{1}+\Delta L_{2}\right)+\frac{\Delta I}{2}\left(L_{n^{\prime}}-L_{2}\right) \\
& +I\left(\Delta L_{3}+\Delta L_{4}\right)+\frac{\Delta I}{2}\left(L_{2}-L_{4}\right) \\
& +I\left(\Delta L_{5}+\Delta L_{6}\right)+\frac{\Delta I}{2}\left(L_{4}-L_{6}\right)+\cdots \\
& +I\left(\Delta L_{m}+\Delta L_{m+1}\right)+\frac{\Delta I}{2}\left(L_{m-1}-L_{m+1}\right) \\
& +I\left(\Delta L_{m+2}+\Delta L_{m+3}\right)+\frac{\Delta I}{2}\left(L_{m+1}-L_{m+3}\right)+\cdots \\
& +I\left(\Delta L_{n-1}+\Delta L_{n}\right)+\frac{\Delta I}{2}\left(L_{n-2}-L_{n}\right) \\
= & I\left(\Delta L_{1}+\Delta L_{2}+\cdots+\Delta L_{m}+\cdots+\Delta L_{n}\right) \\
& +\frac{\Delta I}{2}\left(L_{n^{\prime}}-L_{n}\right) \\
= & I\left(\sum_{k=1}^{m} \Delta L_{k}+\sum_{k=m+1}^{n} \Delta L_{k}\right)+\frac{\Delta I}{2}\left(L_{n^{\prime}}-L_{n}\right) .
\end{aligned}
$$

Due to the low value of $L_{\text {min }}$, the switching frequency in this zone is very high (approximately $12.5 \mathrm{kHz}$ for a peak-to-peak hysteresis band of $0.2 \mathrm{~A}$, section 3.2). As a consequence, the points $n^{\prime}, 1$ and $n$ (shown far from lines $\mathrm{AB}$ and $\mathrm{CD}$ in figure 9 for clarity) will, in practical, lie very close to the respective lines (AB and $C D)$. In this case, from (11) we can write

$$
\begin{gathered}
\sum_{k=1}^{m} \triangle L_{k}=L_{\text {min }}-L_{\text {max }} \\
\sum_{k=m+1}^{n} \triangle L_{k}=L_{\text {max }}-L_{\text {min }}
\end{gathered}
$$

and

$$
L_{n^{\prime}}-L_{n} \approx 0 \text {. }
$$


Substituting the values from (12) to (11) we get $\sum \Delta \psi_{k}=0$, which indicates a numerically bounded $\psi$. To put this simply, it can be said that $\psi$ resets in each electrical period. Hence, the bi-polar hysteresis switching has been used to control the current in the concerned phase ( $\mathrm{R}$, here). It has been verified by electro-magnetic simulation and ensured in the practical experiments that the iron parts of the diagnostic phase do not saturate (section 3.1). This will ensure that measurement of unsaturated phase inductance is truly done.

\section{Experimental results and discussion}

Figure 10 shows the block diagram of the complete hardware set-up. The field and the armature winding of the DCmachine are left unexcited throughout the experiment (noload). Three of the phases of the motor (initially, phase-Y, phase-B and phase-G) are operated in the usual mode of sequential switching using the position sensor pulses whereas the diagnostic phase (initially, $\mathrm{R}$ here), irrespective of the rotor position, is controlled to limit the current within a set band to obtain the complete unsaturated $L(\theta)$ profile of the phase. The process is separately repeated for all the remaining phases. The experiment is conducted at a low voltage of $40 \mathrm{~V}$ to avoid the saturation of motor iron (as the primary objective is to determine the $L(\theta)$ profile of the phases of the motor only). At rated voltage/load conditions, the motor iron may get saturated. In this case also, assuming bulk saturation, the method can be utilised to determine the unsaturated phase inductance following $[2,11]$. The proposed method coupled with $[2,11]$ is thus perfectly general even under bulk saturation of the machine iron. This is a very significant point.

\subsection{Selection of average value of the current}

It is already mentioned that the concerned phase (here, R) will be operated with the pulses obtained from the hysteresis controller. Despite limiting the phase current in a set band, there still remains a possibility of saturation occurrence due to wrong selection of average value of the current as the product of ' $I L(\theta)^{\prime}$ may get larger than the rated value of flux linkage. This may lead to bulk saturation of the pole body of the diagnostic phase. This can be separately dealt with using the principle in $[2,11]$ as mentioned earlier. However, the bulk saturation can be avoided by proper selection of average $I$. This is further explained here.

From (1), the flux linkage of the motor for a constant phase current is given by $\psi(\theta)=I L(\theta)$, which gives the overall allowable maximum value of $\psi, \Psi_{\max }=L_{\max } I$. In order to keep the motor in unsaturated state, $\Psi_{\max }$ is limited to $350 \mathrm{mWb}$-turns, which gives the maximum allowable average phase current, $I=3.125 \mathrm{~A}$, for an $L_{\max }$ of $112 \mathrm{mH}$ (found from finite-element method (FEM) simulation, section 4.1). The corresponding value of $i_{i r o n}$, as found from [2, 11], is $0.2 \mathrm{~A}$. To avoid any possibility of saturation of the core, the average value is chosen to be much lower, as $1.5 \mathrm{~A}$, to have a good sensor precision and ADC resolution, though an even lower average value could have been chosen.

\subsection{Selection of hysteresis band}

The motor phase winding equation is given by

$$
V_{d c}=i r+L(\theta) \frac{d i}{d t}+\mathcal{K} i \omega,
$$

where $\mathcal{K}$ is the slope of the inductance $\left(\frac{d L(\theta)}{d \theta}\right)$ at that instant. The flatness of the curve in $L_{\max }$ and $L_{\min }$ regions results in very small value of $\mathcal{K}$ (ideally zero), due to which the term ' $\mathcal{K} i \omega$ ' may be neglected in the said regions. From (13) we get

$$
V_{d c}=i r+L(\theta) \frac{d i}{d t}
$$

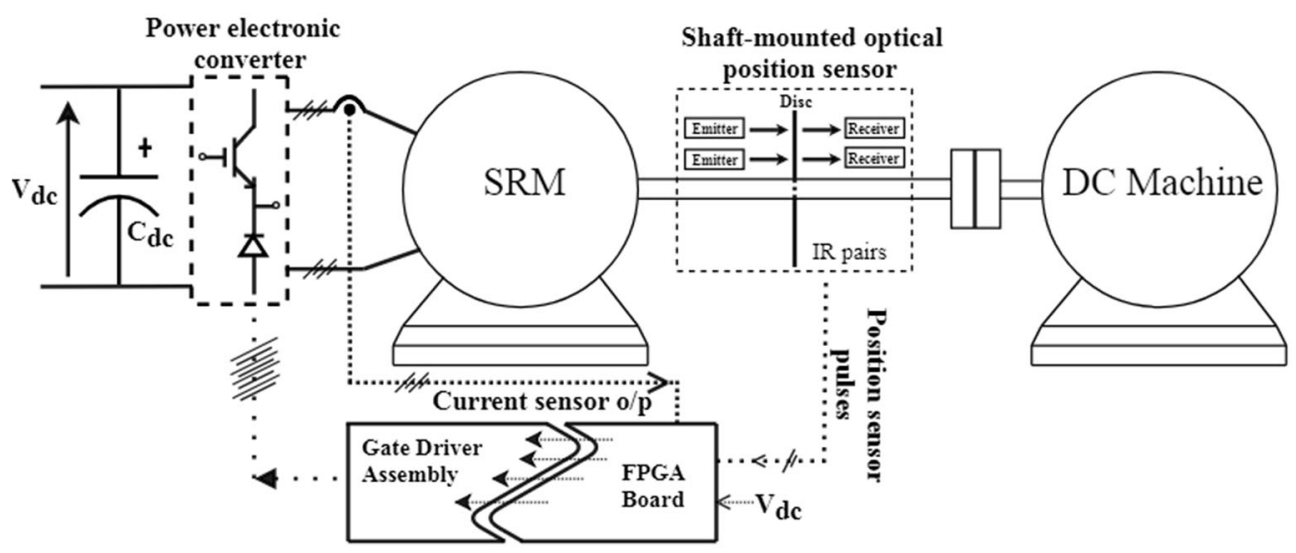

Figure 10. Block diagram of the experimental set-up. 
Further, for the chosen average value of $1.5 \mathrm{~A}$, the ' $i r$ ' drop is equal to $1.05 \mathrm{~V}(1.5 \times 0.7)$, which is less than $3 \%$ of the applied DC-bus voltage and hence it is also neglected. Finally, from (14) we can write

$$
\begin{aligned}
V_{d c} & =L(\theta) \frac{d i}{d t} \\
\Rightarrow \Delta t & =\frac{L \Delta I}{V_{d c}} .
\end{aligned}
$$

In order to maintain a constant current $I=1.5 \mathrm{~A}$ in the phase winding, the hysteresis band should be kept as small as possible (ideally zero). From (15), a narrow band will lead to a very high frequency (in the $L_{\min }$ region) whereas a wide band will result in dominant low-frequency switching ripples in the flux linkage and measured inductance (in the $L_{\max }$ region). As a trade-off between high switching frequency and dominant switching ripples, a peak-to-peak hysteresis band $\left(\triangle I_{p k-p k}\right)$ of $0.2 \mathrm{~A}$ has been selected. The maximum and minimum switching frequency as found in $L_{\min }$ and $L_{\max }$ region for a DC-bus voltage, $V$, of $40 \mathrm{~V}$ and $\triangle I_{p k-p k}$ of $0.2 \mathrm{~A}$ is 12.5 and $900 \mathrm{~Hz}$, respectively. One minor problem encountered during the experiment is the constraint set by the on-board ADC (maximum sampling frequency of $6 \mathrm{kHz}$ ), which cannot adopt a switching frequency of $12.5 \mathrm{kHz}$ (occurring in the $L_{\min }$ region). Hence, to accurately measure the $L_{\min }$ of the winding, a modification has been introduced in the hysteresis band by increasing $\triangle I_{p k-p k}$ to $1 \mathrm{~A}$. It gives a switching frequency of $2.5 \mathrm{kHz}$ and $180 \mathrm{~Hz}$ in the $L_{\min }$ and $L_{\max }$ region, respectively. The results and further modifications are discussed in the subsequent subsection.

\subsection{Waveforms}

Figure 11 shows the waveform of current $(\mathrm{CH} 1)$ and estimated flux linkage $(\mathrm{CH} 2)$ of the diagnostic phase for a hysteresis band of $0.2 \mathrm{~A}$. The high-frequency region (calculated as $12.5 \mathrm{kHz}$ ) is shown encircled in the figure. The flux linkage, $\psi$, has a peak value of $185 \mathrm{mWb}$-turns. The peak-to-peak switching frequency ripple in $\psi$ (whose instantaneous value depends on phase inductance due to a constant hysteresis band) has a maximum value of 22.4 $\mathrm{mWb}$-turns. It is found that the shape of flux linkage of phase- $\mathrm{R}$ is the same as that of the inductance profile, which follows from the basic principle. After the digital division process of $\psi$ by $i$, the on-line computed unsaturated inductance profile of the diagnostic phase is shown in figure 12. Here the maximum value obtained is $117.35 \mathrm{mH}$. The shown waveform (figure 12) is obtained after a lowpass filter having a cut-off frequency of $300 \mathrm{~Hz}$ (which is 10 times the electrical frequency of $30 \mathrm{~Hz}$ of the phase corresponding to a rotational speed of $300 \mathrm{rpm}$ ). The minimum inductance, $L_{\min }$, is found to be almost equal to zero. This is due to unfaithful sampling of phase current by the on-board ADC at a high frequency of $12.5 \mathrm{kHz}$ (shown

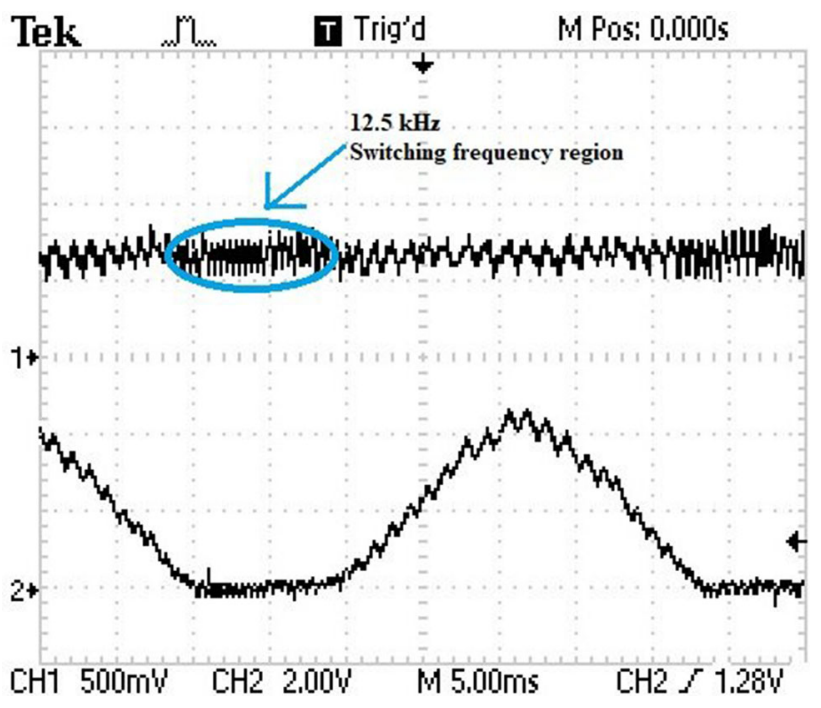

Figure 11. Experimentally obtained current $(\mathrm{CH} 1)$ and flux linkage waveform (CH2) (CH1: $2.4 \mathrm{~A} / \mathrm{V}, \mathrm{CH} 2: 40 \mathrm{mWb}$-turns/V).

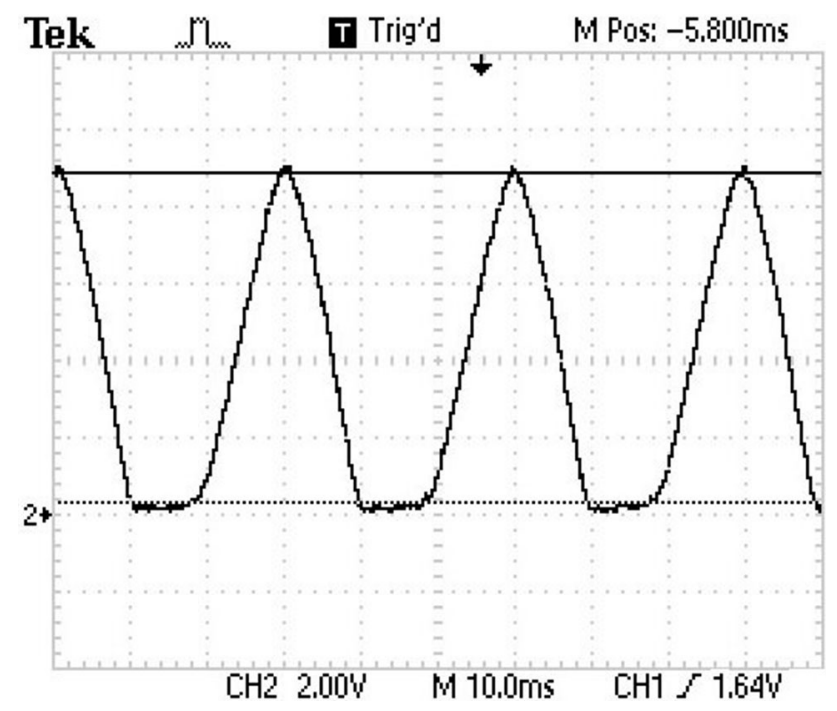

Figure 12. Experimentally obtained phase inductance profile at $\triangle I_{p k-p k}$ of $0.2 \mathrm{~A}(\mathrm{CH} 2: 13.33 \mathrm{mH} / \mathrm{V})$.

encircled in figure 12). As already mentioned, $\Delta I_{p k-p k}$ has been increased to $1 \mathrm{~A}$ to measure $L_{\min }$ accurately. The waveform of measured inductance is shown in $\mathrm{CH} 2$ of figure 13 . Here, the minimum value is found to be equal to $7.46 \mathrm{mH}$. The flux linkage waveform, as shown in $\mathrm{CH} 1$, has low-magnitude high-frequency $(2.5 \mathrm{kHz})$ switching ripples in $L_{\min }$ region whereas the switching ripple magnitudes in $L_{\max }$ region (shown encircled in 'blue' colour) are as high as $200 \mathrm{mWb}$-turns (at switching frequency of $180 \mathrm{~Hz}$ ). The effect is also visible on the $L(\theta)$ profile of the phase as an increased value of $L_{\max }$ by a minimum of $4.5 \%$ ('A', figure 13) with respect to that obtained in figure 12. This is due to the switching ripples occurring in the $L_{\max }$ region (shown encircled in 'red' colour at a frequency of $180 \mathrm{~Hz}$ ), 


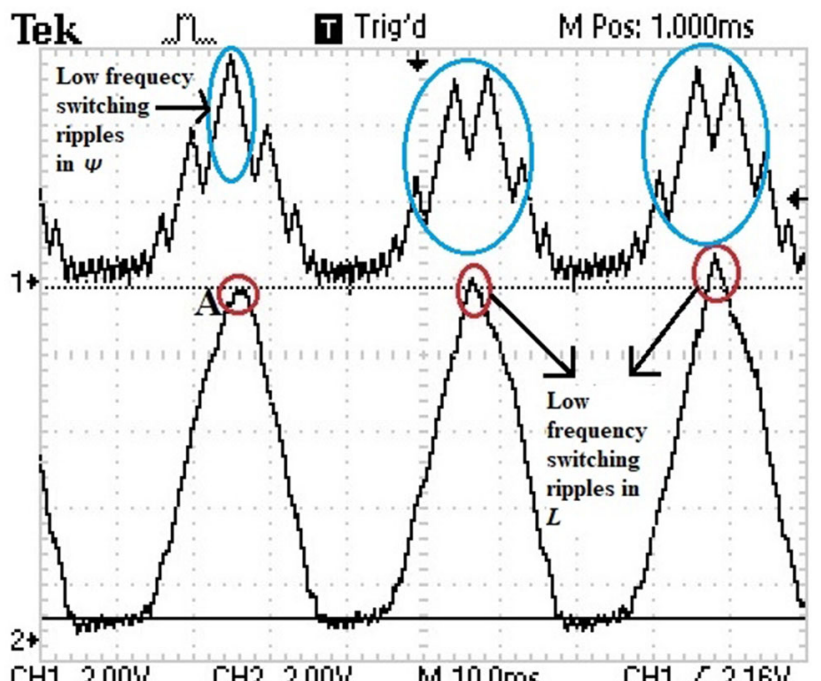

$\mathrm{CH} 12,00 \mathrm{~V} \quad \mathrm{CH} 22,00 \mathrm{~V} \quad \mathrm{M} 10.0 \mathrm{~ms} \quad \mathrm{CH} 1 / 2.16 \mathrm{~W}$

Figure 13. Experimentally obtained flux linkage $(\mathrm{CH} 1)$ and phase inductance profile $(\mathrm{CH} 2)$ at $\Delta I_{p k-p k}$ of $1 \mathrm{~A}(\mathrm{CH} 1: 40 \mathrm{mWb}$ turns/V, CH2: $13.33 \mathrm{mH} / \mathrm{V})$.

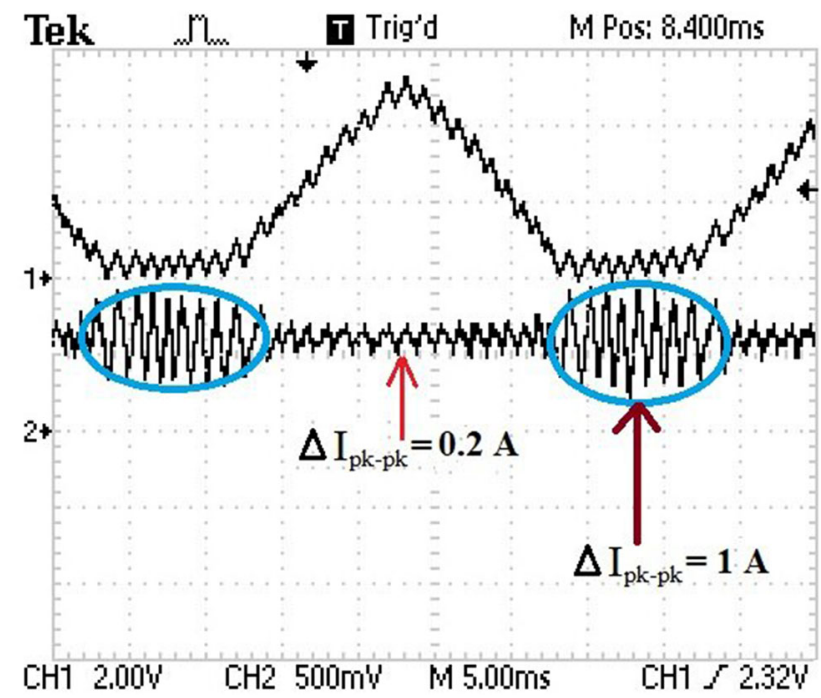

Figure 14. Experimentally obtained current $(\mathrm{CH} 2)$ and flux linkage $(\mathrm{CH} 1)$ waveform of diagnosis phase- $\mathrm{R}$ after final modification (CH1: $40 \mathrm{mWb}$-turns/V, $\mathrm{CH} 2: 2.4 \mathrm{~A} / \mathrm{V})$.

which do not get filtered out by the low-pass filter having a cut-off frequency of $300 \mathrm{~Hz}$.

On the basis of the afore-mentioned experimental results, a final modification has been introduced in the form of variable hysteresis band such that the operating switching frequency value does not cross the lower and upper limits of 1 and $5 \mathrm{kHz}$, respectively. The modification helps in achieving a balance between the ADC sampling frequency and the low-frequency switching ripples. Figure 14 shows the waveforms of current $(\mathrm{CH} 2)$ and estimated flux linkage (CH1) of the diagnostic phases (R, here) after the final modification. In the $L_{\min }$ zone (shown encircled in figure 14), $\Delta I_{p k-p k}$ is taken equal to $1 \mathrm{~A}$. From (13), we get a

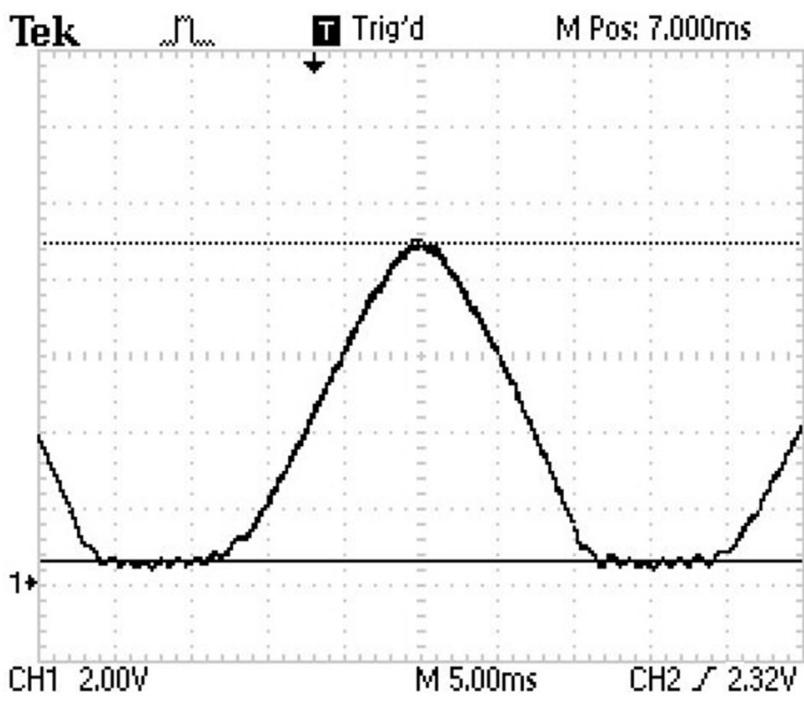

Figure 15. Experimentally obtained inductance profile of the diagnostic phase-R after the final modification $(\mathrm{CH} 1: 13.33 \mathrm{mH} /$ V).

switching frequency of $2.5 \mathrm{kHz}$. As the value of $L(\theta)$ reaches $24 \mathrm{mH}, \Delta I_{p k-p k}$ changes to $0.2 \mathrm{~A}$. The maximum switching frequency of the electrical period, which occurs at $L=24 \mathrm{mH}$, is approximately equal to $5 \mathrm{kHz}$. Figure 15 shows the unsaturated inductance profile of the diagnostic phase- $\mathrm{R}$ after the final modification. The maximum and minimum values are 117.35 and $7.46 \mathrm{mH}$, respectively.

\subsection{Experimental results of measured $L$ of remaining phases.}

As already mentioned, the method has been utilised to measure the unsaturated inductance of the remaining phases. Figures 16, 17 and 18 show the inductance profile of

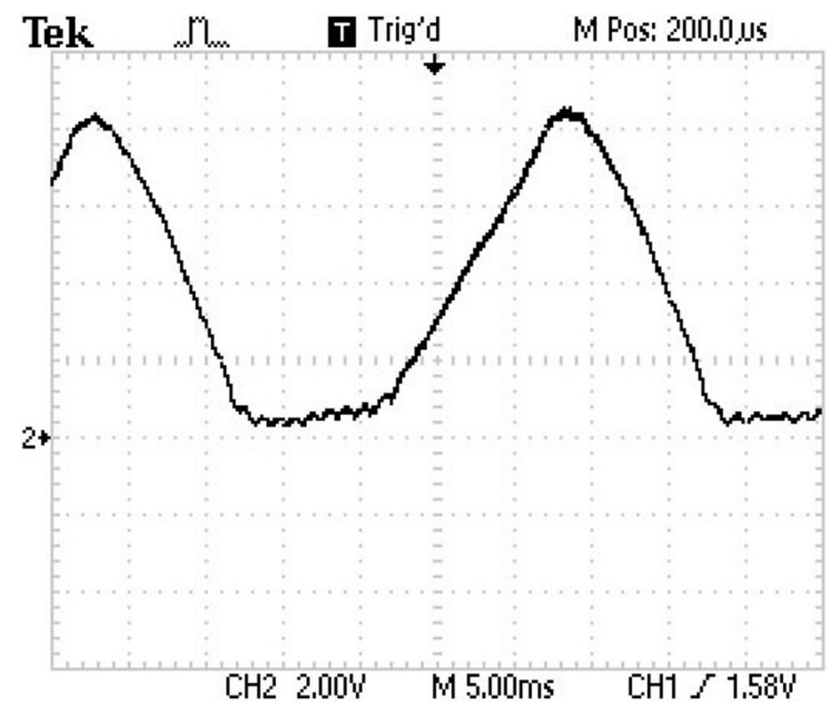

Figure 16. Experimentally obtained inductance profile of phaseY (CH2: $13.33 \mathrm{mH} / \mathrm{V})$. 


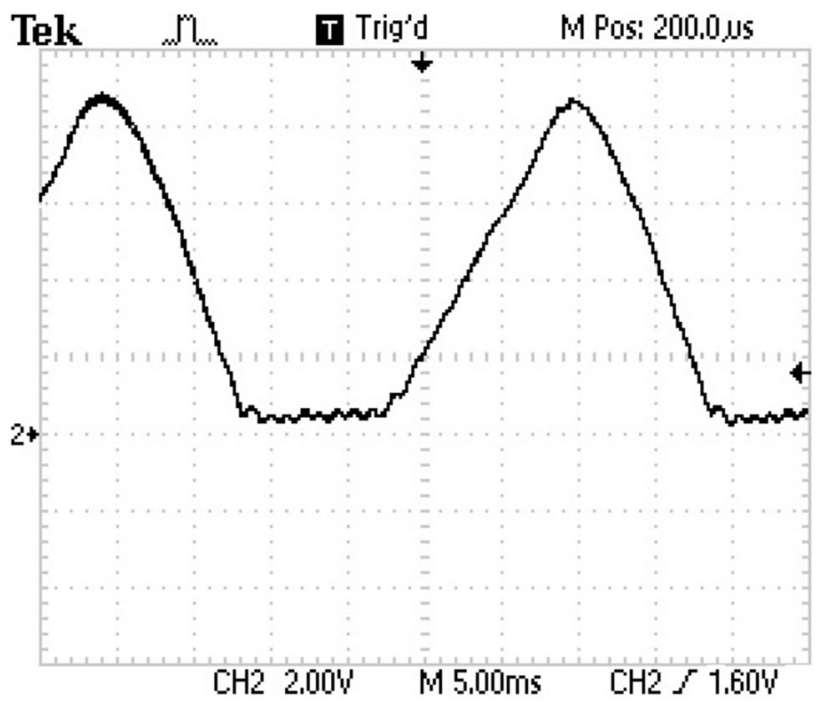

Figure 17. Experimentally obtained inductance profile of phaseB (CH2: $13.33 \mathrm{mH} / \mathrm{V})$.

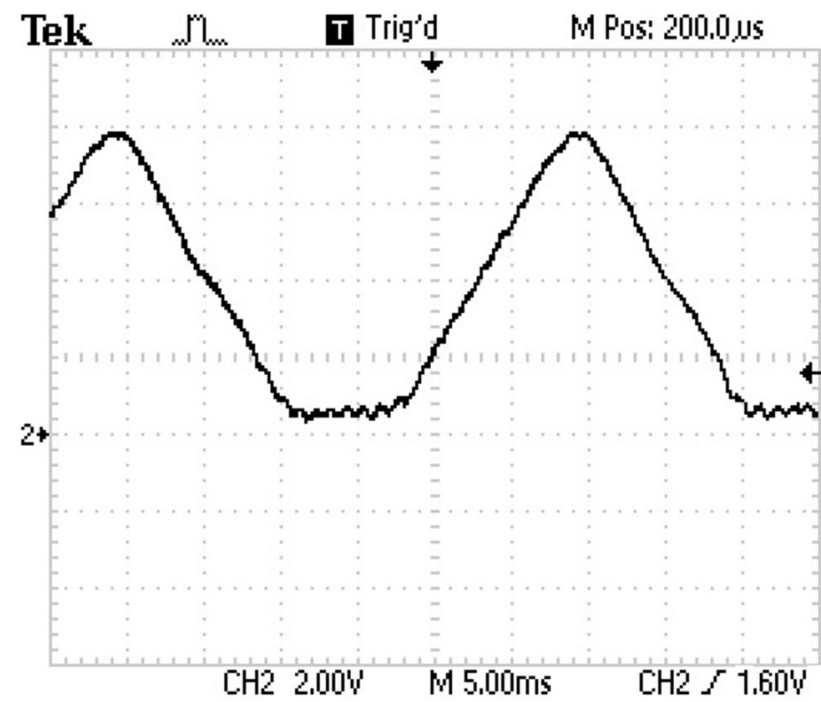

Figure 18. Experimentally obtained inductance profile of phase$\mathrm{G}(\mathrm{CH} 2: 13.33 \mathrm{mH} / \mathrm{V})$

phase-Y, phase-B and phase- $G$, respectively. The maximum and the minimum inductance values of all the four phases are given in table 1.

Table 1. Maximum, minimum value of inductance and peak value of current of all the four phases.

\begin{tabular}{lrcc}
\hline $\begin{array}{l}\text { Concerned } \\
\text { Phase }\end{array}$ & $\begin{array}{r}L_{\max } \\
(\mathrm{mH})\end{array}$ & $\begin{array}{c}L_{\min } \\
(\mathrm{mH})\end{array}$ & $\begin{array}{c}\text { Peak value of phase } \\
\text { current }(\mathrm{A})\end{array}$ \\
\hline Phase-R & 117.35 & 7.46 & 2.40 \\
Phase-Y & 112.02 & 7.46 & 2.70 \\
Phase-B & 116.30 & 7.46 & 2.60 \\
Phase-G & 106.70 & 7.46 & 2.80 \\
\hline
\end{tabular}

It can be observed from table 1 that the maximum values of inductance of the concerned phases (phase-R, phase-Y, phase-B, phase-G) are not equal. Phase- $R$ has the maximum value followed by phase- $B$, phase- $Y$ and phase- $G$ in that order. To justify the different maximum values of phase inductance, the current waveforms of the phases are recorded at normal mode of operation of the motor. They are shown in figures 19 and 20. The peak values of each phase current are given in table 1 . It is found that phase-G has the maximum peak value followed by phase-Y, phase$B$ and phase- $R$ in that order. The order of peak value of current is exact reverse of maximum values of inductance of the phases. Further, the slopes of the current waveforms are different. It can be verified by the time taken by current of each phase to cross a user-determined threshold value. In

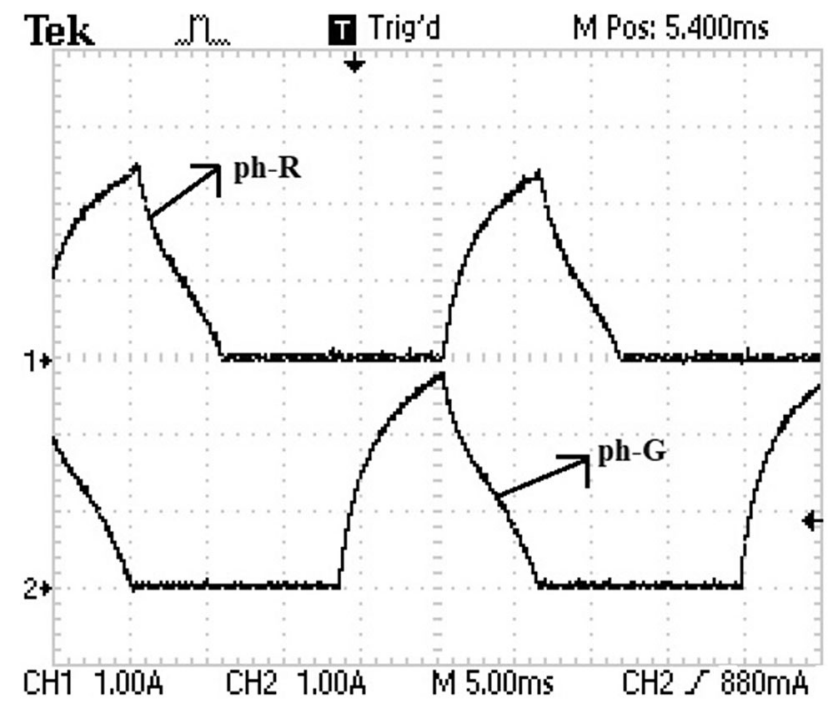

Figure 19. Current waveform of phase- $\mathrm{R}(\mathrm{CH} 1)$ and phase-G $(\mathrm{CH} 2)$ in normal mode of operation at $\theta_{a d v}=0^{\circ}$.

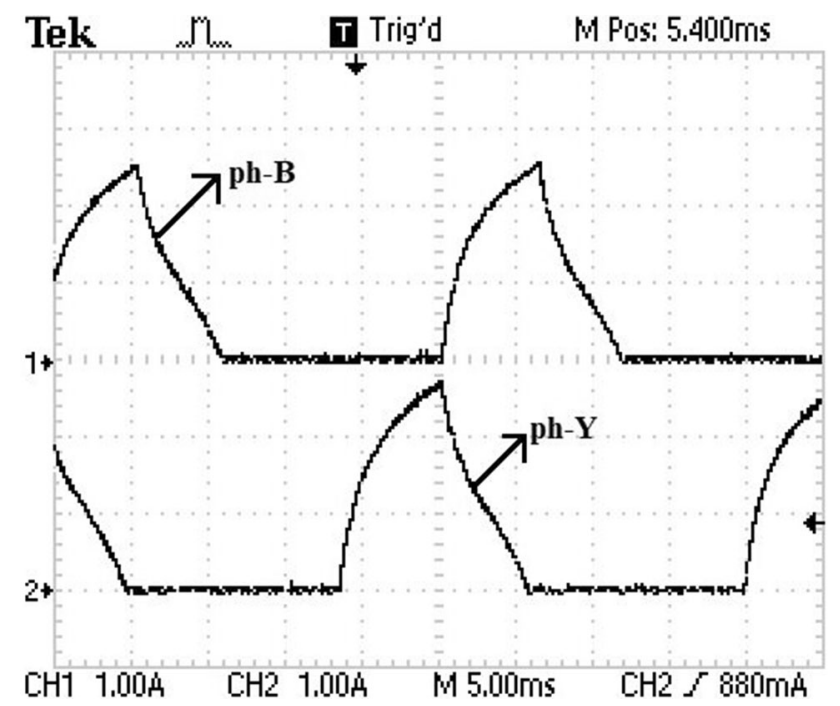

Figure 20. Current waveform of phase-Y $(\mathrm{CH} 2)$ and phase-B (CH1) in normal mode of operation at $\theta_{a d v}=0^{\circ}$. 
the present case, $2 \mathrm{~A}$ has been considered as the threshold value. It is found that time taken by phase-R, phase-Y, phase-B and phase-G is approximately $4,3,3.5$ and $2.5 \mathrm{~ms}$, respectively. These experimental results (figures 19 and 20) validate the different maximum values of measured inductance of respective phases. This finding is particularly interesting and may be used as a tool for diagnosing eccentricity in SRMs. The experimental findings led the authors to try and validate the results against some precise results as may be obtained from tools like FEM-based software packages as reported next.

\section{FEM modelling and validation}

\subsection{Nominal L- $\theta$ profile of the experimental motor}

The nominal unsaturated inductance profile of the motor, as shown in figure 21, is obtained through FEM simulation (using ANSYS-Maxwell) also. The maximum and the minimum values are found to be equal to 112 and $8 \mathrm{mH}$, respectively (assuming electrical steel lamination), which is in very good agreement with the experimentally determined value of 112 and $8 \mathrm{mH}$ in $[2,11]$.

\subsection{Estimation of $\psi$}

Figure 22 shows the circuit diagram of one leg of the asymmetric half-bridge converter of the 4-phase $4 \mathrm{~kW}$ SRM set-up during ON and OFF conditions of the phase. In the simplest mode of operation, switches of each leg of the converter are gated at a phase difference of $15^{\circ}$ mech (= $\left.\theta_{\text {step }}\right)$ in the rising inductance zone to achieve an appropriate average motoring torque. The differential equations of $\psi$ in the afore-mentioned two modes of operation are given by

$$
\frac{d \psi}{d t}=s_{a} V_{d c}-i r
$$

where $s_{a}$ is the switch function, which has a value of 1 and -1 , respectively, during $\mathrm{ON}$ and $\mathrm{OFF}$ conditions of the phase (and ' 0 ' for free-wheeling mode). The Forward Euler method [32] has been used to realise the integration related

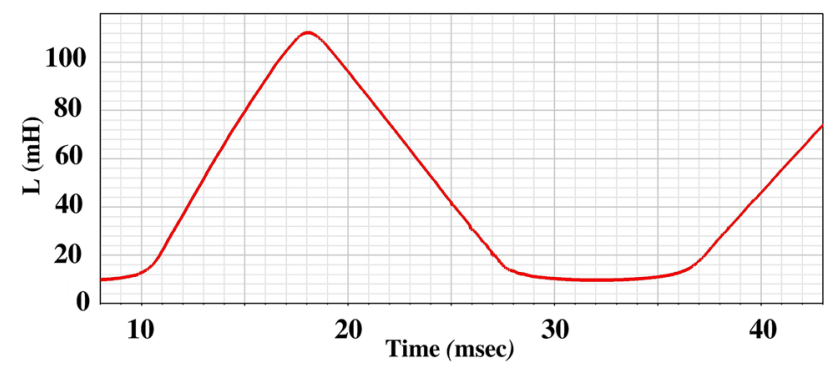

Figure 21. Default $L-\theta$ profile of the motor as obtained using standard FEM package.

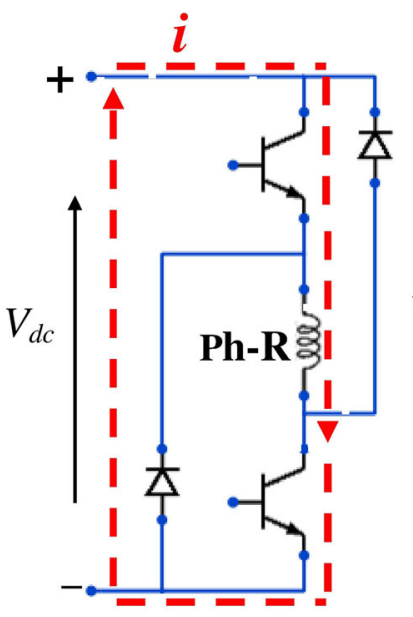

(a)

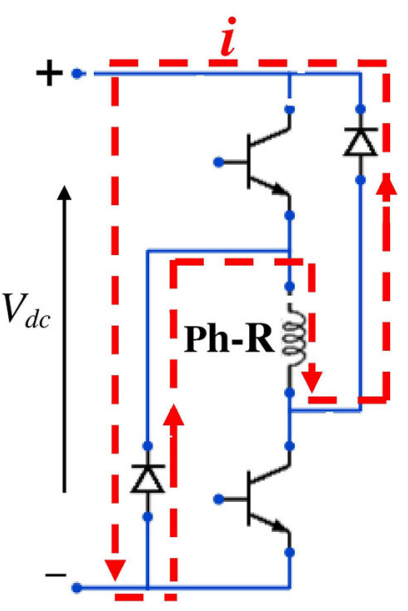

(b)
Figure 22. Circuit diagram of an asymmetric half-bridge converter of one phase of the motor during normal mode of operation: (a) turned-on condition and (b) turned-off condition.

to (16) on the digital platform in order to obtain the $\psi$ of the phase. The mathematical formulation of the method for (16) is given by

$$
\psi_{n+1}=\psi_{n}+\left.\frac{d \psi}{d t}\right|_{n} \Delta T
$$

where $\psi_{n}$ and $\psi_{n+1}$ are the present and the updated values, respectively, and $\left.\frac{d \psi_{n}}{d t}\right|_{n}$ is the slope of the curve at the present instant $(n)$ whereas $\Delta T$ is the integration step size (which is taken as $51.2 \mu \mathrm{s}$ ).

The result of the integration is shown in figure 23. The peak values of phase current and the flux linkage $(\psi)$ of the motor, at a DC-bus voltage of $40 \mathrm{~V}$, are $2.6 \mathrm{~A}$ and 270

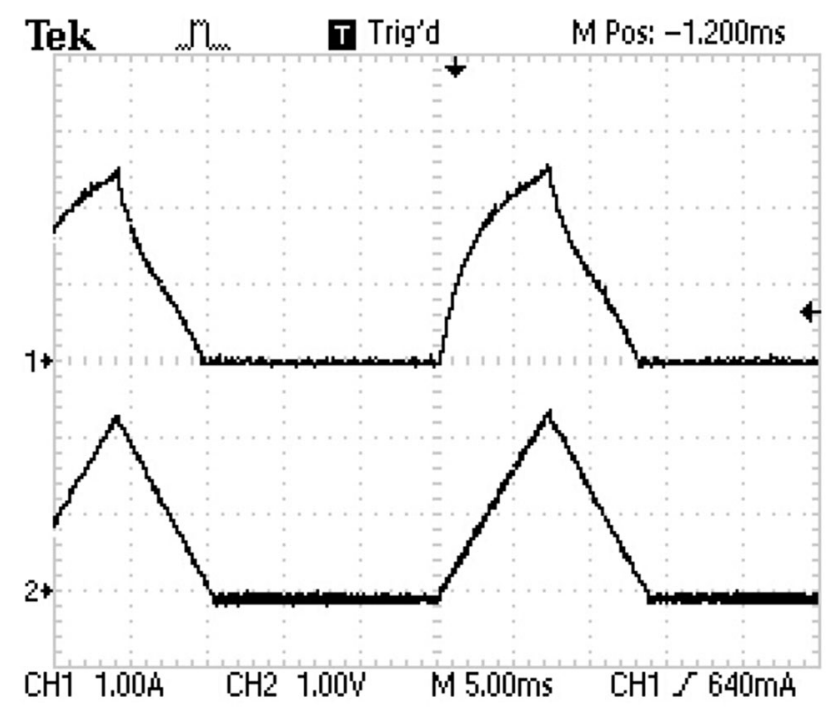

Figure 23. Waveform of flux linkage $(\mathrm{CH} 2)$ and current of phase-R (CH1) at a DC-bus voltage of $40 \mathrm{~V}\left(\theta_{a d v}=0^{\circ}\right)$. CH1: 1 $\mathrm{A} / \mathrm{div}$ and $\mathrm{CH} 2: 120 \mathrm{mWb}$-turns/V. 


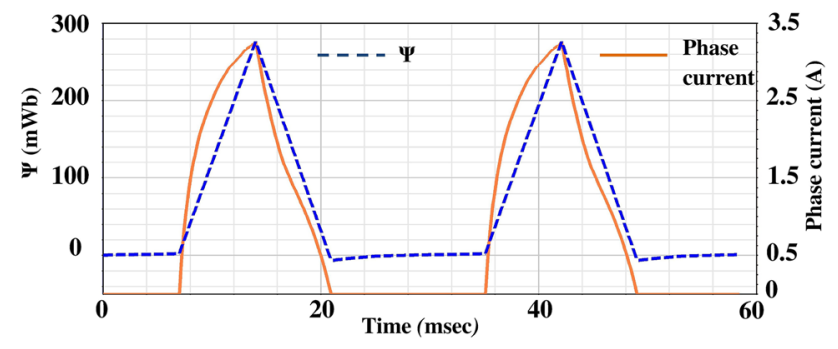

Figure 24. Waveform of FEM simulation of flux linkage and current of phase-R at a DC-bus voltage of $40 \mathrm{~V}\left(\theta_{a d v}=0^{\circ}\right)$.

mWb-turns, respectively. To validate the result, a FEMbased simulation is also performed (assuming electrical steel material [27]) at a DC-bus voltage of $40 \mathrm{~V}$. The value of $\psi_{\max }$ is found equal to $275 \mathrm{mWb}$-turns with a peak phase current of $3 \mathrm{~A}$, as shown in figure 24 . The results are in very good agreement thus validating the choice of electrical steel as a lamination material for unsaturated state of motor iron. In both the cases, motor is rotating at an approximate steady speed of $360 \mathrm{rpm}$ (which can be verified from the time periods of the waveforms shown in figures 23 and 24).

\subsection{Effect of mutual flux}

To analyse the effect of mutual flux between the phases, phase-Y, phase-B and phase-G (shown in yellow, blue, green colours) are operated in the usual manner, i.e., each succeeding phase is switched on at an interval of $15^{\circ}$ mech $\left(\theta_{\text {step }}\right)$ whereas the desired phase- $\mathrm{R}$ (shown in red colour) is kept isolated from the DC-bus by disconnecting it from the converter leg. The simulation is performed at a DC-bus voltage of $40 \mathrm{~V}$. Figure 25 shows the waveform obtained from FEM simulation, where the mutually induced voltage and flux linkage of phase-R have a peak value, respectively, of $2.8 \mathrm{~V}$ and $12 \mathrm{mWb}$-turns. The peak value of mutually induced voltage is approximately $7 \%$ of the applied DC-bus voltage whereas the value of mutual flux linkage is $4.3 \%$ of that obtained in figure 24 during normal mode of operation (at a DC-bus voltage of $40 \mathrm{~V}$ ). This indicates a very weak mutual flux linkage between the phases, which is also supported by the flux line plot of the motor in figure 26 . It

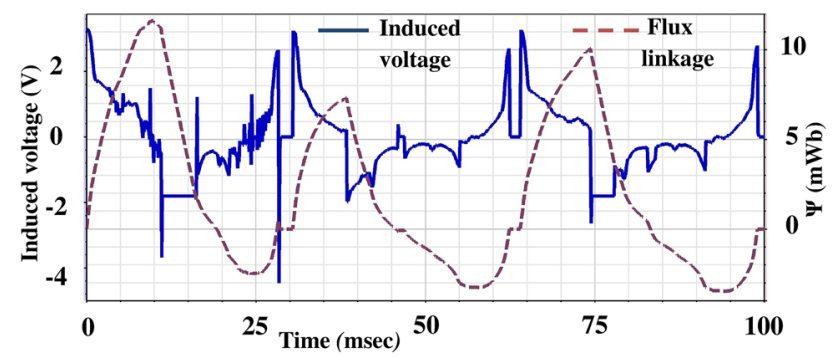

Figure 25. Simulated waveforms of mutual flux and induced voltage of the diagnostic phase-R.

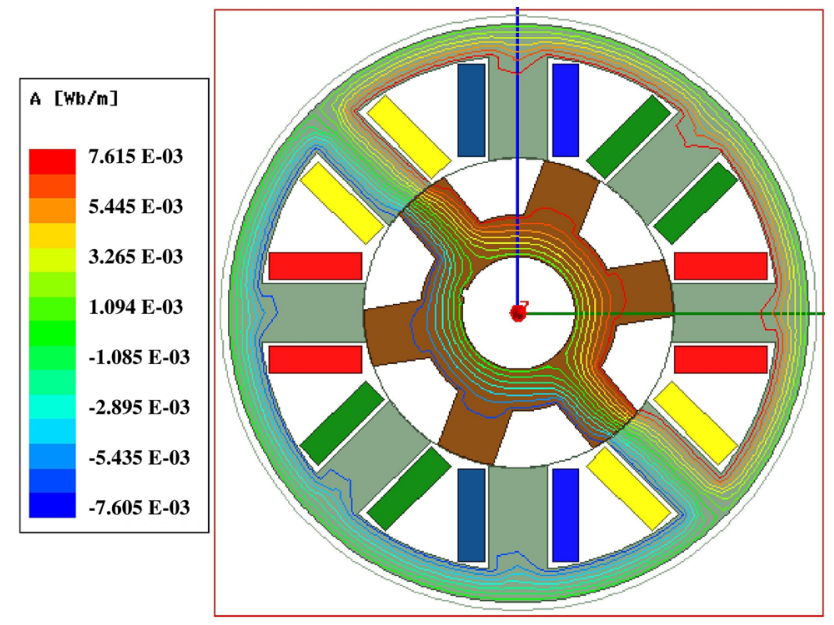

Figure 26. Flux line of the motor at normal operating condition of three phases (phase-Y, phase-B and phase-G) at a DC-bus voltage of $40 \mathrm{~V}$ with phase-R disconnected from DC-bus.

can be observed that no flux crosses the disconnected phase-R.

Due to the very weak mutual coupling between the phases, as obtained by FEM simulation and also detailed in principle in [2], the effect of mutual inductance is neglected. Hence, the proposed method will yield only true unsaturated inductance of the phase.

\subsection{Validation}

Figure 27 shows the 2-D flux density distribution in the FEM model of the motor at a DC-bus voltage of $40 \mathrm{~V}$. The peak flux density in the core of the stator, at the instant of the maximum current in the adjacent phase- $G$, is found to be equal to $0.5 \mathrm{~T}$. The pole body of the phase- $\mathrm{R}$ has a flux density of $0.25 \mathrm{~T}$ with a peak value of $0.4 \mathrm{~T}$ at the tooth tip. It can be observed that the value of the peak flux density is

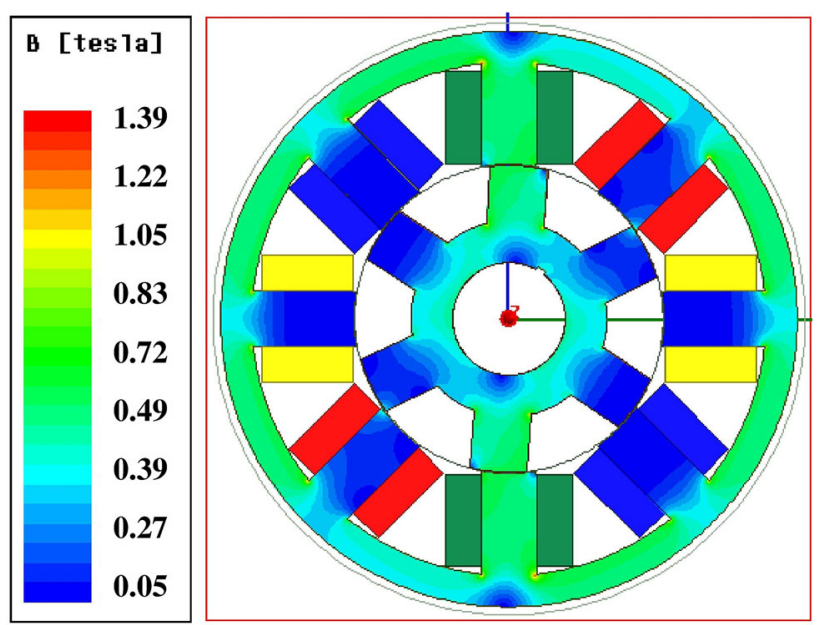

Figure 27. Flux density profile of the motor at the instant of peak current in phase-G. 


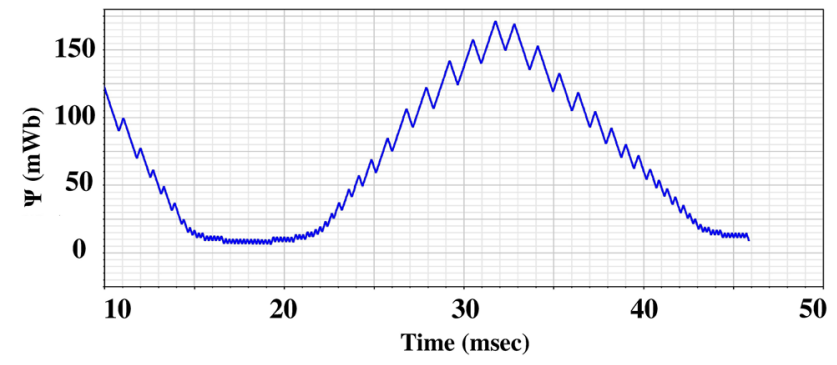

Figure 28. Flux linkage waveform of the diagnostic phase-R.

$33.3 \%$ of the knee point $(1.2 \mathrm{~T})$ of the $B-H$ curve (section 2, figure 3), which justifies the assumption of unsaturated state of the motor.

The current of phase- $\mathrm{R}$ of the motor is maintained constant at an average value of $1.5 \mathrm{~A}$ using bi-polar hysteresis switching. The flux linkage plot of the diagnostic phase is shown in figure 28 . It has a maximum value of $178 \mathrm{mWb}$ turns, which is very close to the experimentally obtained data of $185 \mathrm{mWb}$-turns (figure 11). The corresponding $i_{\text {iron }}$, as found from $[2,11]$, is negligibly small $(<0.1 \mathrm{~A})$. The measured inductance profile obtained in simulation by the proposed dynamic division of $\psi$ by $i$ along with the simulated unsaturated inductance of the model obtained directly from FEM inductance calculation tools (in-built in the standard FEM packages, ANSYS in this case) is shown in figure 29. The maximum and minimum inductances values are 112 and $8 \mathrm{mH}$, respectively, which differ by $4.7 \%$ and $6.75 \%$, respectively, from the experimentally obtained results.

\subsubsection{Comparison with data available in published literature}

The Oulton-make SRM, used in the present experimental work, has been already calibrated by Sengupta and coworkers $[2,11]$. The air gap inductance of the motor, having maximum and minimum values of 112 and $9 \mathrm{mH}$, respectively, is obtained for half electrical pitch in discrete

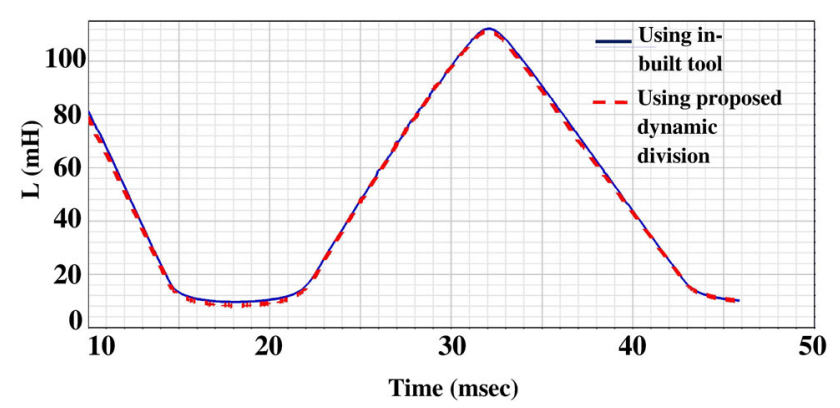

Figure 29. Comparison of phase inductance versus position plot obtained from FEM of the diagnostic phase-R using in-built tools and the proposed dynamic division.

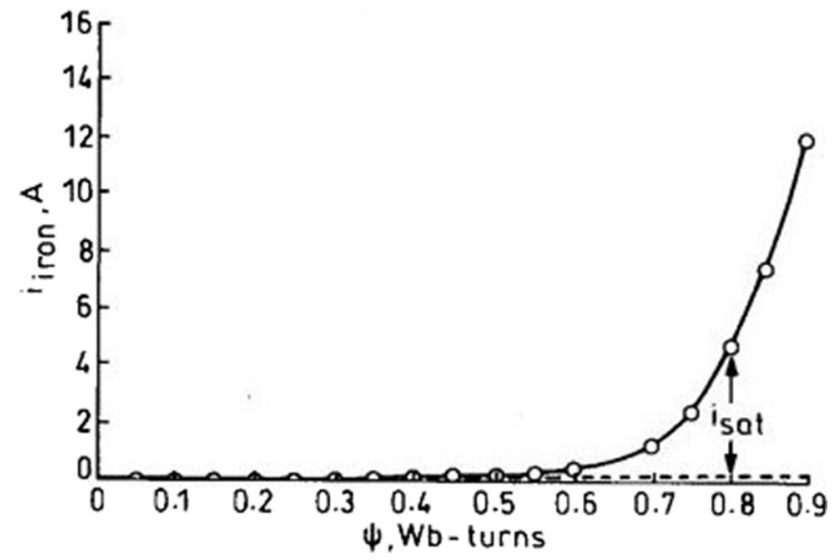

Figure 30. Predicted $\left(i_{\text {iron }}-\psi\right)$ characteristics of Oulton motor [11].

rotor position. The same is also compared to the analytical result obtained by Pohl's method. The variation of $i_{\text {iron }}$ with $\psi$ for the present Oulton motor is shown in $[2,11]$ (also shown in figure 30 for quick reference). It is found that at low saturation ( $\psi \leq 400 \mathrm{mWb}$-turns $)$, ATs required in the iron parts are negligibly small $(<<0.3 \mathrm{~A})$. In the present experimental work, for the selected average phase current of 1.5 A (section 3.1), ATs required in the iron parts are less than $5 \%$. The maximum error introduced in the evaluation of phase inductance, following (3), with respect to the air gap inductance (following (4), as obtained in $[2,11])$, is thus $<5.5 \%$. Thus, the proposed method, which computes the unsaturated inductance profile of the motor, also predicts the air gap inductance of the phase with a marginal error of $<5.5 \%$. It is also evident from the experimental result, where the maximum and minimum values $(117.35$ and $7.46 \mathrm{mH})$ of measured unsaturated inductance of the phase differ by $4.7 \%$ and $6.75 \%$ from $[2,11]$ values (112 and $9 \mathrm{mH}$, respectively). The obtained results are in very good agreement with those published in $[2,11]$.

\subsection{Possible sources of error in the present experimental method}

The variation of resistance of the phase winding, which may occur due to skin effect and temperature variations, may be some of the major causes of error, especially in the computation of the flux linkage (since $\psi=\int(v-i r) d t$ ). The effective resistance of the phase winding increases, which may be compensated by introducing proper adaptive corrections depending on the value of phase current and frequency.

Error may also get introduced due to the digital division, numerical integration, quantisation of data and the low resolution of the sensors, though utmost care has been taken to eliminate the same. 


\section{Possible application in SRM condition monitoring}

In case of actual practical applications, in light-loaded conditions (which is a common and intermittent occurrence in drives), when the required load torque can be contributed by any three phases, the windings can be chosen in sequence, one at a time, for the measurement of phase inductance by the proposed method. This can be then compared to the corresponding pre-stored measured inductance of the phases for the purpose of in-process fault identification/detection, i.e., condition monitoring of the motor phases. This process does not need the motor to be taken out of operation, and hence may be of particular interest in dynamic condition monitoring. Particularly, eccentricity-related faults [33] may be diagnosed using this method, which is foreseen to have wide applicability when SRM drives get wider acceptance and use.

Further, the method can also be utilised for parameter estimation and design validation of an SRM.

\section{Conclusions}

This paper presents a novel, simple and generic method to obtain the unsaturated inductance profile of an SRM that is already installed in a set-up or an application, without any extra hardware with respect to the sensor-less method presented in $[2,11]$. It is shown that the flux linkage when divided by the respective phase current under unsaturated condition yields the air gap inductance of the phase with a marginal error of less than $5 \%$ with respect to $[2,11]$ value. Coupled with the method in $[2,11]$, this can work even under bulk saturation of the motor. N-R method has been used to implement the digital division process in the FPGA platform. A suitable switching strategy has been selected to restrict the operating point in the initial linear rising region of $B-H$ curve (shown encircled in figure 3), which prevents the motor from getting saturated during the measurement process. Effects of mutual flux between the phases and saturation of the core, in the course of measurement, have been analysed by FEM simulations. It is found that the motor remains in the unsaturated state during the process. The effect of mutual flux between the phases is also negligible. Finally, the analysis has been utilised to perform experiments on a 4 $\mathrm{kW}, 1500 \mathrm{rpm}$ Oulton-make SRM where the obtained $L_{\text {unsat }}-\theta$ profile of the diagnostic phase- $\mathrm{R}$ is further validated and calibrated by FEM simulation and comparisons to the value available in the published literature. The experimental results are found to be in a close agreement with FEM results and $[2,11]$ with a maximum error of $6.75 \%$. Apart from this, the inductance of the remaining phases is also measured using the same process. This paper also suggests a possible application of the proposed method for in-process eccentricity and fault diagnosis and in-condition monitoring.

\section{Acknowledgements}

The authors would like to acknowledge the co-operation received from the research colleagues at the APE Laboratory, Department of Electrical Engineering, IIEST Shibpur, and from the institute authorities. Assistance received from Mr N Dutta needs special mention.

\section{Appendix}

\section{Dimensions and rating of the Oulton motor}

The detailed dimension of the motor is available in [11]. The same has been again presented here in table 2 . The rating of the motor is shown in table 3 .

Table 2. Mechanical dimension of the motor [11].

\begin{tabular}{lll}
\hline S1. no. & Stator dimension & \multicolumn{1}{c}{ Value } \\
\hline 1. & No. of phases & 4 \\
2. & No. of teeth & 8 \\
3. & Stack length & $150.5 \mathrm{~mm}$ \\
4. & Stator O.D. & $179.5 \mathrm{~mm}$ \\
5. & Stator bore & $96.4 \mathrm{~mm}$ \\
6. & Yoke I.D. & $160 \mathrm{~mm}$ \\
7. & Slot opening & $20.86 \mathrm{~mm}$ \\
8. & Tooth width & $17 \mathrm{~mm}$ \\
9. & Tooth height & $31 \mathrm{~mm}$ \\
10. & Tooth face arc & $17 \mathrm{~mm}$ \\
11. & Turns per pole & 80 \\
12. & Air gap & $0.4 \mathrm{~mm}$ \\
& Rotor dimension & \\
13. & No. of teeth & 6 \\
14. & Rotor O.D. & $95.6 \mathrm{~mm}$ \\
15. & Rotor I.D. & $60 \mathrm{~mm}$ \\
16. & Tooth width & $18 \mathrm{~mm}$ \\
17. & Slot opening & $32.06 \mathrm{~mm}$ \\
18. & Shaft diameter & $35 \mathrm{~mm}$ \\
\hline
\end{tabular}

Table 3. Nominal ratings of the motor.

\begin{tabular}{ccl}
\hline S1. no. & Name & \multicolumn{1}{c}{ Value } \\
\hline 1. & DC-bus voltage, $V_{d c}$ & $300 \mathrm{~V}$ \\
2. & Power, $P_{o}$ & $4 \mathrm{~kW}$ \\
3. & Speed, $N$ & $1500 \mathrm{rpm}$ \\
4. & Torque, $\Gamma$ & $25.47 \mathrm{Nm}$ \\
5. & Number of stator tooth, $N_{s}$ & 8 \\
6. & Number of rotor tooth, $N_{r}$ & 6 \\
\hline
\end{tabular}




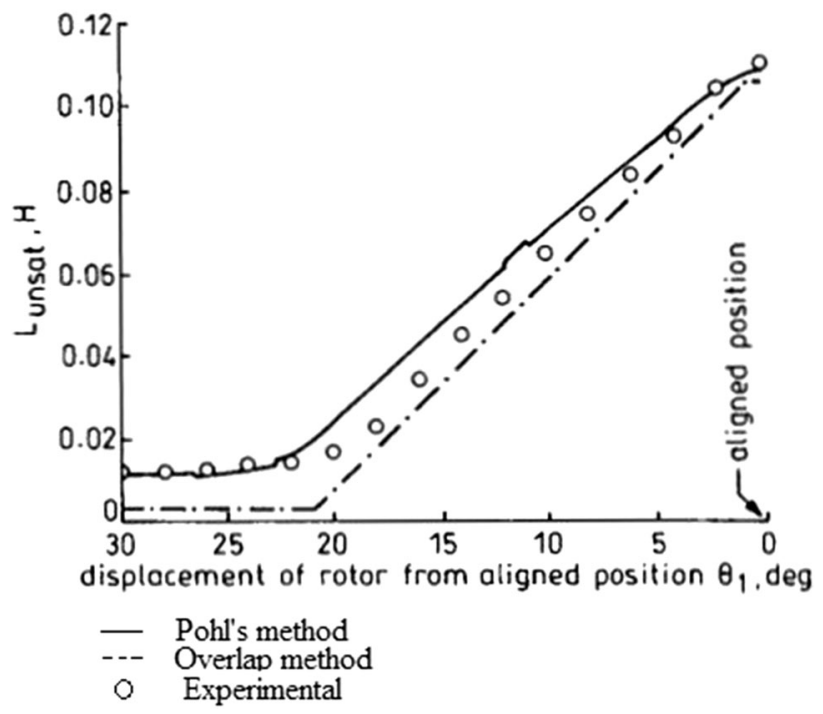

Figure 31. Comparison of $L_{\text {unsat }}$ against $\theta$ for different methods of calculation with experimental result [11].

\section{Waveform of $\psi-i_{\text {iron }}$ and experimentally obtained $L_{\text {unsat }}$}

The waveforms of $\psi-i_{\text {iron }}$ and experimentally obtained $L_{\text {unsat }}$ are shown in [11]; they have been again presented here for quick reference in figures 30 and 31, respectively.

\section{References}

[1] Venkatratnam K 2008 Special electrical machines. Hyderabad, India: Universities Press

[2] Sengupta M 1999 Theory, performance prediction and indirect rotor position sensing of a switched reluctance motor under bulk saturation. PhD Thesis, Department of Electrical Engineering, IIT Kharagpur

[3] Sengupta M, Das S and Sengupta A 2010 Elements of design, fabrication and analysis for a light SR Motor. Germany: VDM Verlag Dr. Muller

[4] Miller T J E 1993 Switched reluctance motors and their control. In: Monographs in Electrical and Electronic Engineering. Hillsboro: Magna Physics

[5] Krishnan R 2001 Switched reluctance motor drives. Boca Raton, Florida: CRC Press

[6] Radun A 1998 Analytical calculation of the switched reluctance motor's unaligned inductance. IEEE Trans. Magn. 35(6): 4473-4481

[7] Materu P and Krishnan R 1990 Analytical prediction of SRM inductance profile and steady-state average torque. In: IEEE Industry Application Society Annual Meeting Conference Record, pp. 214-223

[8] Kuai S, Rallabandi V and Ionel D 2017 Sensorless control of three phase switched reluctance motor drives using an approximate inductance model. In: Proceedings of the IEEE International Electric Machines and Drives Conference (IEMDC), pp. 1-6
[9] Ozden S, Manav G and Dursun M 2018 ANN based magnetic field and inductance modeling of double sided linear switched reluctance motor. In: Proceedings of the 5th International Conference on Electrical and Electronics Engineering, pp. 133-137

[10] Xiang Q, Sun Y and Ji X 2011 Modeling inductance for bearingless switched reluctance motor based on PSOLSSVM. In: Proceedings of the Chinese Control and Decision Conference (CCDC), pp. 800-803

[11] Venkatratnam K, Bhattacharya T K and Sengupta M 1999 Theory, performance prediction and indirect sensing of rotor position of a switched reluctance motor under saturation. IEE Proc.- EPA 146(6): 667-677

[12] Pohl R 1946 Theory of pulsating field machines. J. IEE 93(31): 37-47

[13] Murthy S S, Singh B and Sharma V K 1997 A frequency response method to estimate inductance profile of switched reluctance motor. In: Proceedings of the IEEE International Conference on Power Electronics and Drive Systems (PEDES), pp. 181-187

[14] Ferkova Z, Suchy L and Cernohorsky J 2017 Measurement of switched reluctance motor parameters. In: Proceedings of the 19th International Conference on Electrical Drives and Power Electronics (EDPE), pp. 287-290

[15] Radimov N, Ben-Hail N and Rabinovici R 2005 Inductance measurements in switched reluctance machines. IEEE Trans. Magn. 41(4): 1296-1299

[16] Zhang P, Cassani P A and Williamson S S 2010 An accurate inductance profile measurement technique for switched reluctance machines. IEEE Trans. Ind. Electron. 57(9): 2972-2979

[17] Treek D, Matuschek P, Brauer H J, Schoenen T and De Doncker R W 2009 An automatic identification of phase inductance for operation of switched reluctance machines without position sensor. In: Proceedings of the IEEE International Electrical Machines and Drives Conference, pp. 1005-1009

[18] Ehsani M and Ramani K R 1996 Direct control strategies based on sensing inductance in switched reluctance motors. IEEE Trans. Power Electron. 11(1): 74-82

[19] Hamouda M and Szamel L 2017 Accurate measurement and verification of static magnetization characteristics for switched reluctance motors. In: Proceedings of the Nineteenth International Middle East Power Systems Conference (MEPCON), pp. 948-953

[20] Ustun O 2009 Measurement and real-time modeling of inductance and flux linkage in switched reluctance motors. IEEE Trans. Magn. 45(12): 5376-5382

[21] Li X and Shamsi P 2015 Inductance surface learning for model predictive current control of switched reluctance motors. IEEE Trans. Transp. Electrif. 1(3): 287-297

[22] Cai J and Deng Z 2012 Sensorless control of switched reluctance motor based on phase inductance vectors. IEEE Trans. Power Electron. 27(7): 3410-3423

[23] Wang J, Ma Q, Zhang P and Ye W 2017 Sensorless control of a four phase switched reluctance machine with novel bridge converter. In: Proceedings of the Chinese Automation Congress (CAC), pp. 6674-6679

[24] Cai J, Lu L, Liu Z, Jia H, Zhao X and Xu F 2017 An inductive position sensor with switched reluctance motor 
structure. In: Proceedings of the 20th International Conference on Electrical Machines and Systems (ICEMS), pp. 1-4

[25] Ralev I, Max S and Doncker R 2018 Accurate rotor position detection for low-speed operation of switched reluctance drives. In: Proceedings of the 18th International Power Electronics and Motion Control Conference (PEMC), pp. $483-490$

[26] Venkataratnam K, Sengupta M, Chattopadhyay A K and Bhattacharjee R 2003 Development and experimental validation of a novel analytical model for performance prediction of SR motors under saturation. In: Proceedings of the IEEE Fifth International Conference on Power Electronics and Drive Systems, pp. 948-953

[27] Magnetic hysteresis. 2018-03-09, available at: https://www. electronics-tutorials.ws/electromagnetism/magnetic-hyster esis.html

[28] Kreyszig E 2006 Advanced engineering mathematics. New Delhi: Wiley India Pvt. Limited
[29] Nenadic N M and Mladenovic S B 2005 Fast division on fixed-point DSP processors using Newton-Raphson method. In: Proceedings of the International Conference on Computer as a Tool, pp. 705-708

[30] Vestias M P and Neto H C 2011 Revisiting the NewtonRaphson method for decimal division. In: Proceedings of the 21 st International Conference on Field Programmable Logic and Application, pp. 136-143

[31] Hoyle D F Function approximation. 2018-04-05, available at: https://people.ucsc.edu/ ealdrich/Teaching/Computa tionGroup/Slides/lec4.pdf

[32] Ramanarayanan V 2007 Lecture notes of short term course on FPGA real time controller and simulator. Bangalore, India: IISc

[33] Chaudhury S B, Sengupta M and Mukherjee K 2013 Experimental study of induction motor misalignment and its online detection through data fusion. IET Electr. Power Appl. 7(1): 58-67 